\title{
The Performance and Plume Characterization of a Laboratory Gridless Ion Thruster with Closed Electron Drift Acceleration
}

\author{
Peter Y. Peterson", and Alec D. Gallimore ${ }^{\dagger}$ \\ The University of Michigan, Ann Arbor, MI, 48109, US
}

The design and characteristics of a laboratory-model two-stage gridless ion thruster with closed electron drift are presented. The scaling and design of the electron bombardment ionization stage and the acceleration stage are described. The performance characterization of the thruster in single and two-stage is presented and discussed. The thruster plume was characterized with an ExB probe and gridded Faraday probe.

\section{Nomenclature}

$\alpha \quad$ Acceptance angle

$\mathrm{A}_{\text {Collector }} \quad$ ExB ion collection area

$\mathrm{a}_{1} \quad$ Collimator entrance orifice diameter

$\left[\mathrm{m}^{2}\right]$

Collimator entrance orifice diameter
Collimator entrance orifice diameter

$[\mathrm{mm}]$

$\begin{array}{ll}a_{2} & \text { Collimator entrance orifice diameter } \\ a_{3} & \text { Drift tube entrance orifice diameter }\end{array}$

$[\mathrm{mm}]$

ExB collector diameter

$[\mathrm{mm}]$

$\begin{array}{ll}\alpha & \text { Acceptance angle } \\ \text { B } & \text { Magnetic field vector }\end{array}$

CEX Charge-Exchange collision

$\mathrm{d}_{\text {plates }}$

Electrode spacing

e Electron charge

Force

I accel Total acceleration stage current

$I_{\text {sp }} \quad$ Specific Impulse

I $I_{\text {Beam }} \quad$ Ion beam current

$I_{\text {ion }} \quad$ Ion current from ionization stage

$\mathrm{I}_{\mathrm{e}} \quad$ Electron leakage current

$\mathrm{I}_{\text {probe, } \mathrm{i}} \quad$ Ion current fraction

$\mathrm{I}_{\mathrm{GP}} \quad$ Gridded Faraday probe total current

$\mathrm{I}_{\mathrm{C}} \quad$ Gridded Faraday probe pressure corrected total current

$\mathrm{M}_{\text {propellamt }}$ Ion mass

$\dot{m}_{a} \quad$ Anode propellant mass flow rate

$\mathrm{n}_{\mathrm{b}} \quad$ Neutral background density

$\mathrm{P}_{\text {accel }} \quad$ Acceleration stage power

$\mathrm{P}_{\text {ion }} \quad$ Ionization stage power

pase $\quad$ Base pressure of the facility

T Thrust

$\mathrm{T}_{\text {coil }} \quad$ Electromagnetic coil temperature

\footnotetext{
${ }^{*}$ Graduate Student, Plasmadynamics and Electric Propulsion Laboratory, AIAA member.

${ }^{\dagger}$ Professor, Department of Aerospace Engineering, Plasmadynamics and Electric Propulsion Laboratory, Associate Fellow AIAA.
} 
$\begin{array}{ll}\mathrm{V}_{\text {accel }} & \text { Acceleration Potential } \\ \mathrm{V}_{\text {plates }} & \text { Electrode potential } \\ \mathrm{V}_{\text {pass }} & \text { ExB ion pass potential } \\ \mathrm{Z} & \text { Degree of ionization } \\ \mathrm{Z}_{\mathrm{Collimator}} & \text { Collimator length } \\ \mathrm{Z}_{\mathrm{ExB}} & \text { ExB length } \\ \mathrm{Z}_{\text {Drift }} & \text { Drift tube length } \\ \Delta \mathrm{V}_{\text {accel- } \phi} & \text { Potential difference } \\ \beta_{0.45 \mathrm{~m}} & \text { Divergence angle from } 0.45 \mathrm{~m} \text { gridded Faraday probe } \\ \beta_{0.95 \mathrm{~m}} & \text { Divergence angle from } 0.95 \mathrm{~m} \text { gridded Faraday probe } \\ \eta_{\mathrm{T}} & \text { Thruster efficiency } \\ \eta_{\mathrm{u}} & \text { Propellant utilization efficiency } \\ \phi & \text { Potential } \\ \phi_{\mathrm{Xe}}{ }^{+} & \text {Measured Xe }{ }^{+} \text {pontential } \\ \sigma_{\mathrm{CEX}} & \text { Charge Exchange Cross-Section } \\ \mathrm{m}_{\mathrm{i}} & \text { Mass of propellant ion } \\ \zeta_{\mathrm{i}} & \text { Ion species fraction }\end{array}$

$[\mathrm{V}]$
$[\mathrm{V}]$
$[\mathrm{V}]$
$[-]$
$[\mathrm{mm}]$
$[\mathrm{mm}]$
$[\mathrm{mm}]$
$[\mathrm{m} / \mathrm{s}]$
$\left[{ }^{\circ}\right]$
$\left[{ }^{\circ}\right]$
$[\%]$
$[\%]$
$[\mathrm{V}]$
$[\mathrm{V}]$
$\left[\mathrm{m}^{2}\right]$
$[\mathrm{kg}]$

\title{
I. Introduction
}

$\mathrm{P}$ revious investigations conducted by NASA Glenn Research Center (GRC) evaluated high-specific impulse Hall thrusters designed to provided the following characteristics [1-7].

\author{
Power $=2.3 \mathrm{~kW}$ \\ Thrust $=100 \mathrm{mN}$ \\ Specific Impulse $=3200$ seconds \\ Lifetime $=8000$ hours
}

Two of these devices, the D-80 anode layer thruster, and the SPT-1 stationary plasma thruster (SPT), were both evaluated at GRC. A third device, the BHT-HD-1000 Hall thruster was evaluated at the Busek Co. The results of these investigations are discussed in Refs. [5-7]. Each of these investigations indicated that Hall thruster efficiency had a maximum specific impulse of less than 3200 seconds. A follow-on investigation at GRC and the University of Michigan was initiated to investigate the observed variation in efficiencies at voltages greater than $500 \mathrm{~V}$. During this follow-on investigation three Hall thrusters were designed. The first Hall thruster was the P52 two-stage magnetic layer Hall thruster [3, 4, 8]. The P5-2 utilized a two-stage intermediate electrode and a plasma lens magnetic field topography [9]. The second thruster was the single-stage NASA-173Mv2 which has demonstrated efficient operation at high-voltages [3]. The third thruster was the NASA-173GT two-stage magnetic layer thruster with a separate electron bombardment ionization stage (173 represents the outer diameter and the GT acronym stands for griddless ${ }^{\ddagger}$ thruster). This thruster, which is the subject of the present investigation, utilized a separate independent ionization source in addition to the ionization and acceleration mechanisms of a Hall thruster.

The work presented here describes the NASA173GT measured performance and plume characterization for single and two-stage

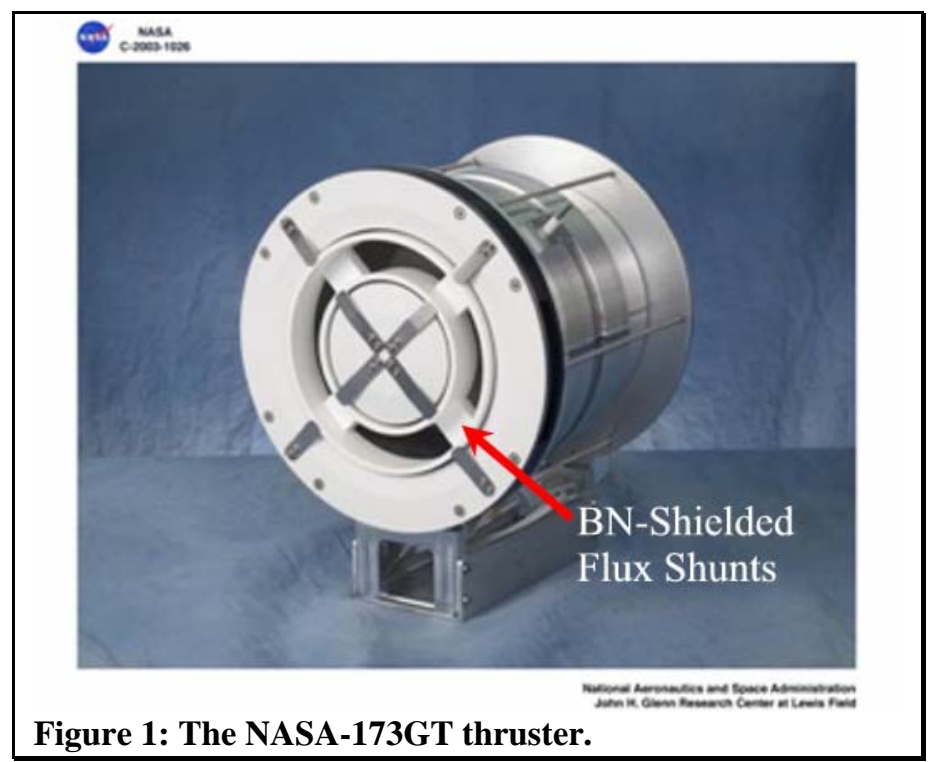

"The terms "gridded' and "griddless" have been used in the past as a means to identify the difference between Ion and Hall electrostatic thrusters. For this work, the acronym GT will stand for an ion thruster with a Hall acceleration mechanism. 
operation $^{\S}$. The plume was characterized with two plasma diagnostic techniques: an $\mathbf{E x B}$ probe for determining the ion species fractions and a gridded Faraday probe for ion current density and plume divergence measurements. A discussion of the performance and the plume results are presented and future work is suggested.

\section{Thruster}

A photograph and diagram of the NASA-173GT is shown in Figure 1 and Figure 2, respectively.

\section{A. Hall Acceleration Stage}

The NASA-173GT was designed based on the P5 5 kW class laboratory Hall thruster [10, 11]. The diameter and width of the P5 Hall thruster were retained for the acceleration stage of the NASA-173GT as a result of the availability of existing performance and plasma measurements for the P5 and the P5-2 [4, 8, 11-19]. The depth of the acceleration stage was chosen to reduce the losses to the acceleration channel walls while still providing sufficient geometric space

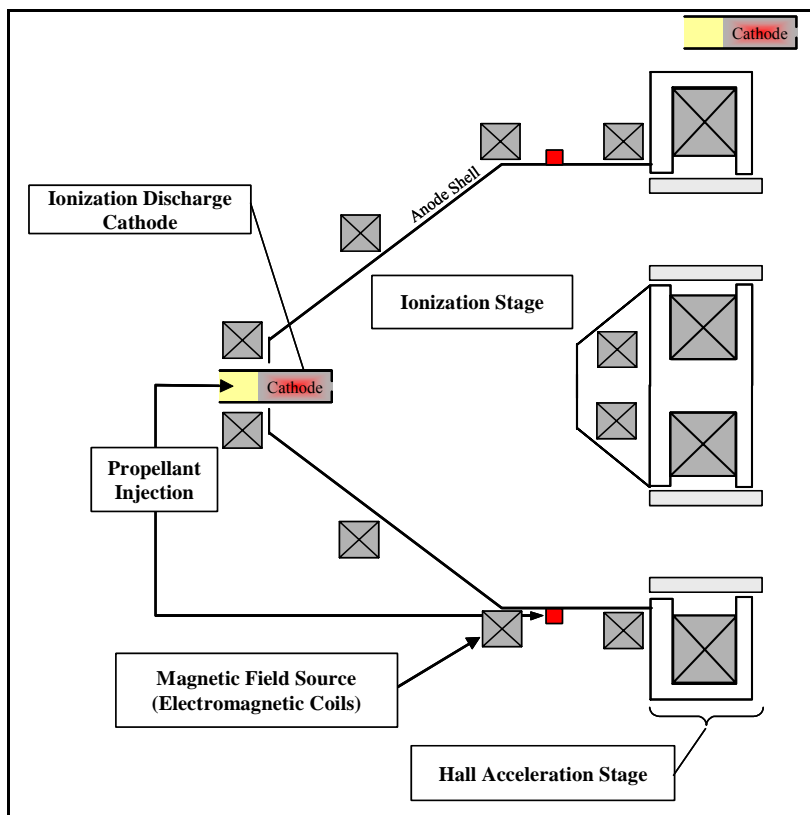

Figure 2: Diagram of the NASA-173GT. for the magnetic circuit.

The propellant distribution of the NASA-173GT occurred in the ionization stage, as illustrated in Figure 2. The design provided uniform propellant distribution. Integrating the ionization stage with the acceleration stage required four magnetic field shunts to allow the required magnetic field profile.

\section{B. Electron Bombardment Ionization Stage}

An electron bombardment ionization source was chosen for the NASA-173GT ionization stage ${ }^{* *}$ The electron bombardment ion source was composed of an applied magnetic field that serves as a magnetic insulation layer to prevent the primary electrons from flowing directly towards the anode. The magnetic insulation layer caused a mirroring effect, which enhanced ionization efficiency. The magnetic insulation layer was designed to produce a large volume in the ionization stage in which the field was below $50 \mathrm{G}$. This region is also referred to as the "fieldfree" region.

The scaling and design of the ionization stage of the NASA-173GT was based on the dimensions of existing laboratory and engineering model ion thruster. These designs have the following characteristics:

1) Neutral propellant density was sufficiently high to assure a electron mean free path suitable for ionization of the propellant with minimal double-charged ion production [20].

2) Small surface-area-to-volume ratio to reduce ion recombination and primary electron losses to the walls [21].

3) A ring-cusp design, which has been shown to provide the lowest ion-production cost for electron bombardment type ionization sources [21-23].

4) An efficient propellant distribution configuration such as a "reverse-feed" plenum, which has been shown to increase the propellant utilization by as much as 5\% [24-26].

The anode shell of the NASA-173GT ionization stage was fabricated from non-ferrous stainless steel. The NASA-173GT open area fraction ${ }^{\dagger \dagger}$, for neutral propellant escaping the ionization stages, was determined to be $38 \%$. Compared to the SOA NSTAR ion thruster [27] the NASA-173GT open area fraction was approximately 50\% larger.

\footnotetext{
$\S$ This paper is an overview of this author's dissertation material on the NASA-173GT.

** Radio frequency $(\mathrm{RF})$ or microwave $(\mu \mathrm{W})$ ionization sources were discounted because of their complexity, and high equipment cost.

${ }^{\dagger}$ The open area fraction is defined as the amount of area exposed to the vacuum outside the thruster that neutral particles can thermally drift through without undergoing ionization in the ionization chamber.
} 


\section{Magnetic Circuit}

A three-dimensional, magnetostatic, finite-element software package was used to design the magnetic circuits of the NASA-173GT. The magnetic circuit design had two primary requirements: to establish a plasma lens field topography in the acceleration stage and to accomplish this in shortest axial length to minimize loss of ions to the walls. During the design of the ionization stage magnetic circuit the following characteristics were selected: the type of magnetic field source, the number of cusps in the ionization stage, the topography of the field-free region, and the profile and intensity of the magnetic field at the cathode. Electromagnetic coils were selected to provide the applied magnetic field in the ionization stage due to the flexibility that adjustable coils provide. The final magnetic field topographies for the Hall acceleration and ionization stages of the NASA-173GT are illustrated in Figure 3. The plasma lens field topography shares similar properties with other NASA Hall thrusters $[4,8]$.

\section{Experimental Apparatus}

The performance characterization and plasma property measurements were conducted at NASA GRC's vacuum facility twelve (VF-12). This facility

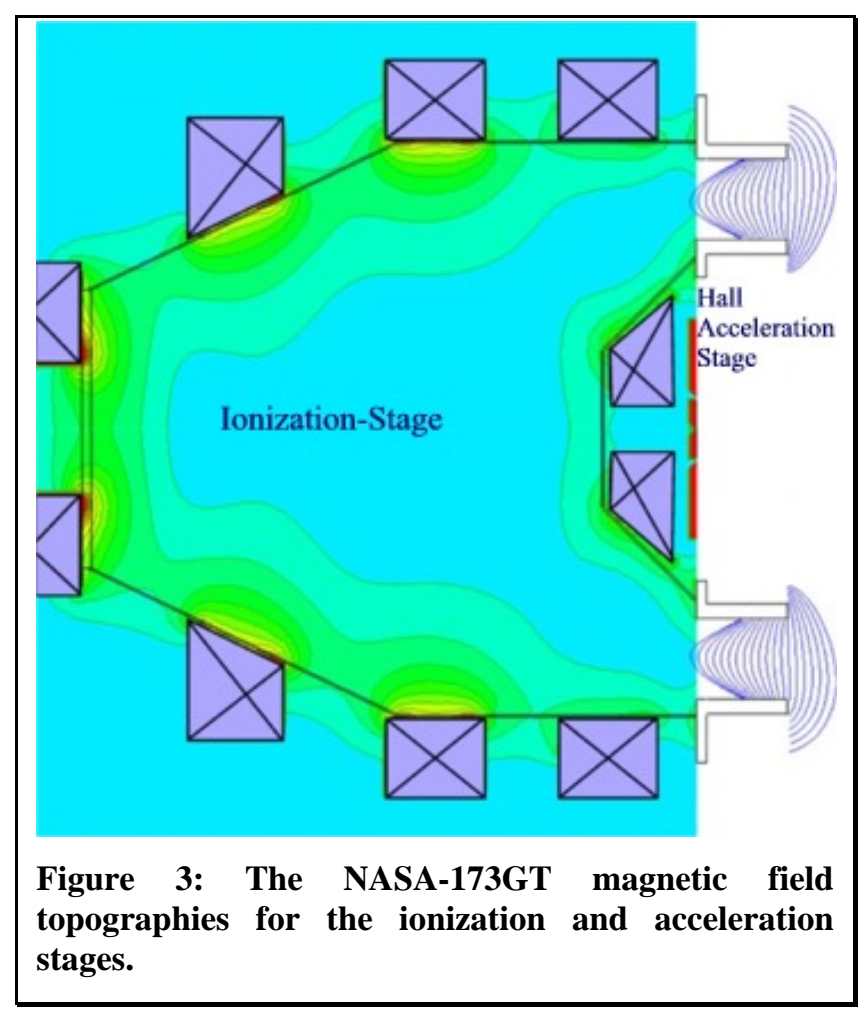
has previously been used for wear testing a $10 \mathrm{~kW}$ T-220 Hall thruster for 1000-hours [28] and for wear testing a D80 anode layer thruster for 1200 hours [29]. VF-12 is now used for GRC's high-voltage Hall thruster development program [3]. For these tests VF-12 was equipped with automated data acquisition, autonomous thruster operation, motion control system for plasma diagnostic devices, and integral high-voltage power console for high-voltage Hall thruster testing. This section contains descriptions of the vacuum facility, power console, propellant mass flow systems, thrust stand, ExB probe, and gridded Faraday probes employed to characterize the NASA-173GT.

\section{A. Vacuum Facility}

The VF-12 is a $3 \mathrm{~m}$ in diameter by $9 \mathrm{~m}$ in length vacuum chamber with a pumping speed in excess of $1,000,000$ liters per second (air) provided by liquid helium cryopanel surfaces. Non-condensable gases are pumped by 1000 liter per second (air) turbo pump.

\section{B. Power Consoles}

The input power for the two stages of the NASA-173GT was provided by two separate power consoles comprised of commercially available power supplies. The primary power console was composed of two acceleration stage power supplies each capable of producing a constant voltage output ranging from $0-2000 \mathrm{~V}$ at current levels of $0-10 \mathrm{~A}$ or constant voltage output ranging from $0-1200 \mathrm{~V}$ at current levels of $0-16 \mathrm{~A}$. The primary power console also contained supplies for six electromagnetic coils and the operation of the hollow cathode. The primary power console contained circuitry needed for autonomous operation when coupled with the data acquisition system. The second power console provided power for the ionization stage of the NASA-173GT. Individual power supplies included heater and keeper power supplies for the ionization stage cathode and a separate supply for the ionization stage discharge. The ionization discharge power supply was selected to provide up to $60 \mathrm{~A}$ of current and 50 volts. The ionization stage power supplies were isolated from ground by three isolation transformers that allowed the power supplies to float to the potential of the acceleration stage.

\section{Propellant Flow System}

The NASA-173GT configuration utilized three independent propellant flow controllers. A combination of the anode plenum and ionization stage cathode flows provided the total propellant flow for the ionization and acceleration stages. A combination of the anode plenum and ionization stage cathode flows provided the total 
propellant flow for the ionization and acceleration stages. The propellant used for the evaluation of the NASA173GT was $99.999 \%$ pure xenon. The xenon was controlled with a 200 SCCM mass flow controller for the anode in the ionization stage, a 100 SCCM flow controller for the ionization stage cathode, and a 20 SCCM flow controller for the acceleration stage cathode. The flow controllers were calibrated before and after testing using a constant volume flow technique. The observed error between flow calibrations was no greater than $1 \%$ for the anode, $1.2 \%$ for the ionization stage cathode, and $1.7 \%$ for the acceleration stage cathode.

\section{Thrust Stand}

An inverted pendulum, null-type thrust stand was employed to measure the NASA-173GT performance. The operation and theory of this inverted pendulum null-type thrust stand is described in Refs. [3, 30, 31]. The inclination of the thrust stand was monitored and adjusted during performance characterization to minimize the influence of thermal drift. The thrust stand was surrounded by a copper shell that was water cooled at $20^{\circ} \mathrm{C}$. The thrust stand was calibrated before and after each performance test with an in-situ calibration system comprised of calibrated masses. Pre- and post-calibrations of the thrust stand indicated zero thermal drift and a $1.5 \%$ uncertainty in the thrust measurements.

\section{E. ExB probe}

An ExB probe, also known as a Wien filter, is a plasma diagnostic tool that can be used to measure ion velocity of accelerated plasmas [3234]. ExB probes can distinguish ion species fractions by adjusting either the applied electric or magnetic fields. The distribution of ion velocities can be measured by sweeping the applied electric field strength with a constant magnetic field. Individual velocity peaks are observed corresponding to the

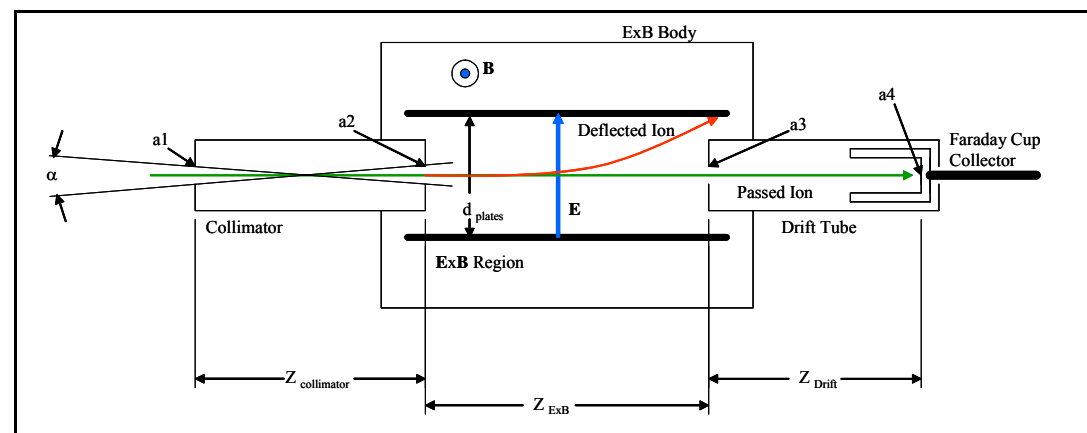

Figure 4: Schematic of an ExB probe. different charge states of the ions.

Components of the ExB probe were the collimator, the $\mathbf{E x B}$ region, and the drift/collector region as illustrated in Figure 4. The ExB probe utilized an elongated Faraday cup in the drift/collector region. The Faraday cup was designed to minimize the influence of secondary electron emission from the collector surface during the collection of accelerated propellant ions as discussed in Refs. [3, 32, 35]. This probe was a similar design of the probes used for testing the SPT-100 [33] and the NASA-173Mv2 [3] Hall thrusters. The relationship between the applied probe voltage and ion velocity use in this investigation is shown in the following equation:

$$
V_{\text {plates }}=B d_{\text {plates }} v_{\text {pass }}=B d_{\text {plates }} \sqrt{\frac{2 e Z \phi}{M_{\text {propellant }}}},
$$

where $V_{\text {plates }}$ is the voltage of the $\mathbf{E x B}$ probe, $B$ is the applied magnetic field strength, and $d_{\text {plates }}$ is the separation distance of the ExB plates.

The entrance orifices of the ExB probe were positioned approximately $2.04 \mathrm{~m}$ downstream of the thruster exit plane with an axial uncertainty of $\pm 0.5 \mathrm{~cm}$. The $\mathbf{E x B}$ probe was positioned radially such that the interrogation area was aligned along the center line of the acceleration stage channel with an uncertainty of $\pm 0.25 \mathrm{~cm}$. Based on this geometry a probe acceptance angle of $0.38^{\circ}$ was calculated [33]. The velocity resolution of the ExB probe was calculated to have a 30\% uncertainty based on this configuration and the probe parameters as described in Ref. [33].

The ion current fractions were determined from the relative peak heights of the ion velocity spectrum based on the following relationship: 


$$
I_{\text {probe }, i}=e Z_{i} n_{i}\left\langle v_{i}\right\rangle A_{\text {Collector }},
$$

where $\mathrm{A}_{\text {Collector }}$ is the area of the ion collection, $i^{\text {th }}$ is for the ion species, and $\mathrm{n}_{\mathrm{i}}$ is the number density of each ion species. Each ion species fraction was determined by expanding equation 2, and solving a system of equations for each ion species fraction $[3,32,35]$.

The uncertainty of the measured ion species fractions was determined by examining the uncertainty of the applied potential across the plates, the magnitude of the applied magnetic field, the selection of the ion species peaks, the distance between the plates, and the influence of charge-exchange (CEX) collisions over the axial distance between the thruster and the ExB probe. The uncertainty in the ion species fractions was determined to be $\pm 2 \%, \pm 25 \%$, and $\pm 96 \%$ for $\mathrm{Xe}+, \mathrm{Xe}++$, and $\mathrm{Xe}+++$, respectively.

\section{F. Gridded Faraday Probe}

Gridded Faraday probes were used to make plasma measurements in the plume of the NASA-173GT. The use of Faraday probes as a means of measuring ion current densities in a flowing plasma is a well established plasma diagnostic tool [36, 37]. Faraday probes are composed of an ion collector plate that is biased to a negative potential sufficient enough to repel electrons. An equivalently biased guard ring is placed around the collector plate to reduce the edge effects. By sweeping a Faraday probe, along a constant radial path through the plume, an ion current density profile can be obtained. This ion density profile can be integrated to determine total ion current and ion beam plume divergence. The total ion current in the plume, calculated from ion current traces measured with simple Faraday over estimates the ion

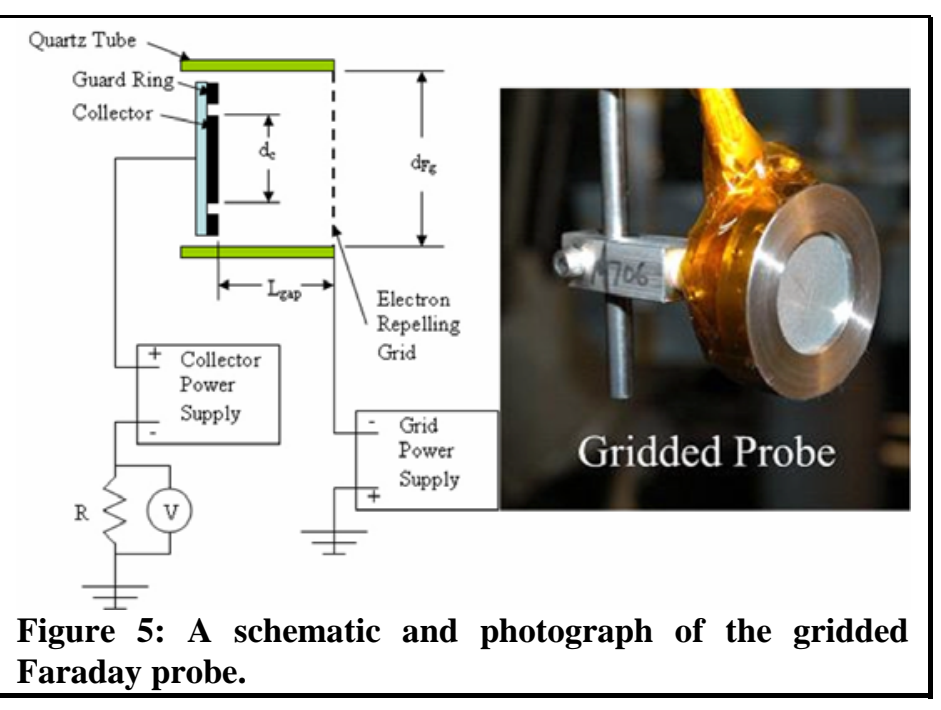
current by as much as $200 \%[11,38]$. This over prediction has been attributed to the influence of low energy background ions such as those created through chargeexchange (CEX).

The Faraday probe employed during the plume characterization of the NASA-173GT contained an additional grid to mitigate this effect. The electron repelling grid added upstream of the collector surface repelled electrons allowing the collector plate to be biased positively. Positively biasing the collector plate allowed it to function as a low ion energy CEX filter. This probe configuration has been demonstrated previously [37]. Excluding the low energy ions allowed for a more accurate estimation of the thruster propellant and current utilizations based on the measured ion beam current. A photograph and schematic of the gridded Faraday probe are illustrated in Figure 5.

Two gridded Faraday probe were rotated through the plume at fixed radial distances of $0.45 \mathrm{~m}$ and $0.95 \mathrm{~m}$. Ion current density were measured at every rotation increment (one degree) throughout the sweep. The total beam current $\left(\mathrm{I}_{\mathrm{B}}\right)$ was calculated from the ion current density traces using the following expression $[11,39]$.

$$
I_{B}=2 \pi \mathrm{z}^{2} \int_{0}^{\pi / 2} j_{z}(\theta) \sin (\theta) d \theta
$$

where $\mathrm{z}$ is the probe distance from the thruster and $\mathrm{j}_{\mathrm{z}}(\theta)$ is the ion current density measured by the collector plate at the angular position, $\theta$. The total ion beam current calculated from equation 3 was thought to provide a reasonable estimation of the ion current carried by high energy ions by excluding low energy CEX ions [40] (neglecting attenuation of the beam by the electron repelling grid). Attenuation of the high energy ion current beam due to the electron repelling grid and CEX was estimated to allow for a calculation of the actual thruster ion beam current based on the following equation: 


$$
\frac{j_{z}(\theta)}{j(\theta)}=\frac{j_{z}(\theta)}{j_{\text {open }}(\theta)} * \frac{j_{\text {open }}(\theta)}{j(\theta)}=(17 \%) * \exp \left(-n_{b} \sigma_{\text {cex }} z\right)
$$

The results were then used to compute the divergence angle of the plume, which was an indirect method of observing the thruster efficiency. The plume divergence $(\beta)$ was defined as the half angle with respect to the thruster centerline in which $95 \%$ of the ion current density occurs for a beam profile from $-90^{\circ}$ to $+90^{\circ}$ [3]. The plume divergence utilization efficiency $\left(\eta_{\beta}\right)$ is defined as the (cosine $\left.\beta\right)^{2}$ efficiency losses [41].

The primary sources of uncertainty for the gridded Faraday probe study of the NASA-173GT were the axial and radial positioning of the probes, the current measurement, the measurement of the open area fraction, the loss of secondary electrons from the collector plate to the guard ring, and CEX collision between the probe and the thruster exit plane.

\section{Results and Discussion}

The NASA-173GT thruster was operated in single and two-stage configurations with stable ion beam extraction. A photograph of the NASA-173GT, in a two-stage configuration, is shown in Figure 6.

\section{A. Single-Stage Performance}

Single-stage performance was obtained by disconnecting the ionization stage power supplies and allowing the ionization cathode to float. The ionization stage electromagnet coils were not used during the single-stage experiments. During single-stage operation $2 \mathrm{mg} / \mathrm{s}$ of xenon propellant was provided through the non-operating ionization cathode. The remainder of the total anode propellant flow was injected through the anode plenum. The single-stage performance was measured with total anode propellant flow rates of $5 \mathrm{mg} / \mathrm{s}$ and $10 \mathrm{mg} / \mathrm{s}$ and acceleration voltages ranging from 100 to $600 \mathrm{~V} \$$. These results are tabulated in Table 1 in the Appendix.

Anode efficiency as a function of applied voltage is shown in Figure 7 for flow rates of 5 and $10 \mathrm{mg} / \mathrm{s}$. The anode efficiency for the $5 \mathrm{mg} / \mathrm{s}$ case reached a maximum between 250 to $400 \mathrm{~V}$ and decreased with further increases in voltage. The anode efficiency

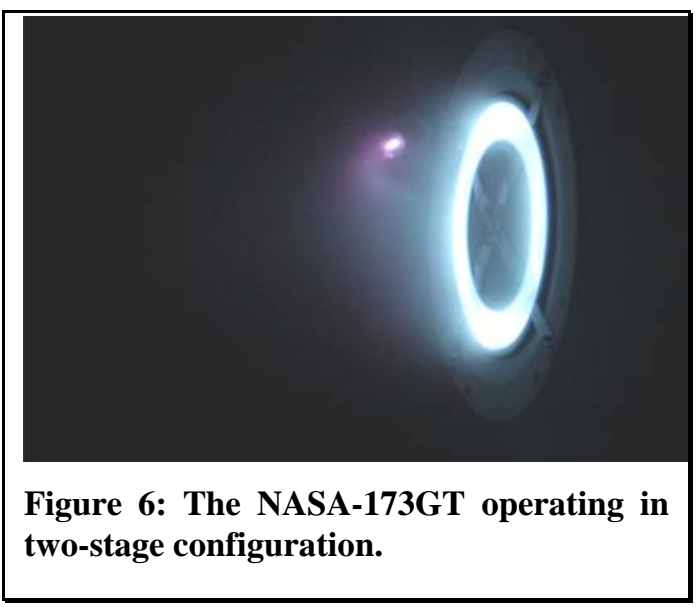
for the $10 \mathrm{mg} / \mathrm{s}$ case reached a maximum at $300 \mathrm{~V}$. Efficiency remained constant as the voltage was increased further. This difference was attributed to the higher propellant density at the $10 \mathrm{mg} / \mathrm{s}$ operating point. The higher propellant flow rate was thought to increase the neutral density in the Hall acceleration stage improving ionization efficiency and decreasing the electron leakage across the applied field.

SOA Hall thrusters operating on xenon exhibit a linear relationship between anode propellant flow rate and discharge current at nominal operating conditions [41]. This relationship for SOA Hall thrusters is normally slightly less than or close to unity, as illustrated in Figure 8. Comparing the discharge current to the flow rate gives an indication of the effectiveness of the thruster to efficiently ionize and accelerate the propellant while simultaneously impeding axial electron current. Figure 8 shows the ratio of the acceleration current to the anode propellant flow rate, expressed in terms of equivalent current, as a function of voltage for the $5 \mathrm{mg} / \mathrm{s}$ and $10 \mathrm{mg} / \mathrm{s}$ cases.

For the $5 \mathrm{mg} / \mathrm{s}$ case this ratio increase at voltages above $150 \mathrm{~V}$ as illustrated in Figure 8 . These data in conjunction with the efficiency data shown in Figure 7 indicated electron leakage current was increasing with voltage since the efficiency decreased above this voltage. This conclusion was substantiated by the results from the gridded Faraday probe as subsequently discussed in sections IV-0.

The specific impulses obtained from single-stage operation at total anode propellant flow rates of $5 \mathrm{mg} / \mathrm{s}$ and 10 $\mathrm{mg} / \mathrm{s}$ are presented in Figure 10. These data are also compared to the theoretical specific-impulse and a corrected theoretical specific impulse that accounts for multiple charged ions, plume divergence, current $\left(\mathrm{I}_{\text {Beam }} / \mathrm{I}_{\text {accel }}\right)$, and propellant utilization efficiency $[3,42]$ in Figure 10. The specific impulse results of the NASA-173GT were below

$\$$ The NASA-173GT operation envelope was limited to 500 to $600 \mathrm{~V}$ as a consequence of a contaminated acceleration stage magnetic circuit, which was limited to $40 \%$ of the designed maximum applied field. 
the theoretical specific impulse curve. The corrected specific impulse, calculated based on the results measured with the ExB and gridded Faraday probes, matched the measured specific impulse results. This corrected specific impulse indicated the NASA-173GT was hampered by a large electron leakage current $\left(\eta_{\text {current }}<0.5\right)$ and plume divergence $\left(\eta_{\text {current }}<0.6\right)$.

The electron leakage current is thought to be due to the interface between the ionization and acceleration stages of the NASA-173GT. During the thruster testing the surface of the $\mathrm{BN}$ shields perpendicular to the direction of the Hall current glowed, as can be seen in Figure 9. This interaction may have allowed a large percentage of the Hall current to interact with the internal structure of the thruster enhancing electron leakage. This conclusion was supported by performance data and data from the gridded Faraday probe.

\section{B. Two-Stage Performance}

The two-stage performance characteristics were measured for total anode propellant flow rates of $5 \mathrm{mg} / \mathrm{s}$ and $10 \mathrm{mg} / \mathrm{s}$ at acceleration voltages of 100 to $600 \mathrm{~V}^{\text {H木 }}$, ionization currents of 15 and 25 Amperes, and ionization-stage powers from 100 to 600 Watts. During twostage operation $2 \mathrm{mg} / \mathrm{s}$ was provided through the operating ionization cathode. The remainder of the total anode propellant flow was injected through the anode plenum. Twostage anode efficiency as a function of applied voltage is shown in Figure 11 for flow rates of 5 and $10 \mathrm{mg} / \mathrm{s}$. For the $5 \mathrm{mg} / \mathrm{s}$ propellant flow rate case anode efficiency reached a maximum between 200 to $350 \mathrm{~V}$ and decreased with increasing acceleration voltage. For the $10 \mathrm{mg} / \mathrm{s}$ propellant flow rate case anode efficiency reached a maximum at $300 \mathrm{~V}$ for the range of power levels.

As with the single stage data the ratio of the acceleration current to the anode propellant flow rate was considered. Figure 12 illustrates this ratio as a function of the acceleration voltage for $5 \mathrm{mg} / \mathrm{s}$ and $10 \mathrm{mg} / \mathrm{s}$ cases.

For the $5 \mathrm{mg} / \mathrm{s}$ case the ratio increased from 100 to $600 \mathrm{~V}$. The anode efficiency of the $5 \mathrm{mg} / \mathrm{s}$ two-stage case, shown in Figure 11, increased with acceleration voltage between 200 and $350 \mathrm{~V}$, and then decreased with further increases in voltage. The results from Figure 11 and Figure 12 suggested that these changes in efficiency were the 
result of electron leakage. Above $350 \mathrm{~V}$ increases in electron leakage dominated increases in ion current. The interaction of the Hall current with the flux shunt shields again appeared to limit the anode efficiency of the NASA-173GT at higher acceleration potentials.

The two-stage specific impulse data for propellant flow rates of $5 \mathrm{mg} / \mathrm{s}$ and $10 \mathrm{mg} / \mathrm{s}$, acceleration voltages ranging from 100 to $600 \mathrm{~V}$, and the ionization power levels from 200 to 600 Watts are presented in Figure 13. A comparison of the theoretical specific-impulse and multiple term corrected specific-impulses [42] for both 5 and $10 \mathrm{mg} / \mathrm{s}$ cases are also presented in Figure 13. These data also suggest electron leakage and plume divergence was the dominant loss mechanisms during two-state operation as similarly observed during single stage operation.

\section{Single and Two-Stage Operation Comparison}

The performances results of the single and two-stage were equivalent, which indicated no observable improvements. The ratio of thrust-to-acceleration power

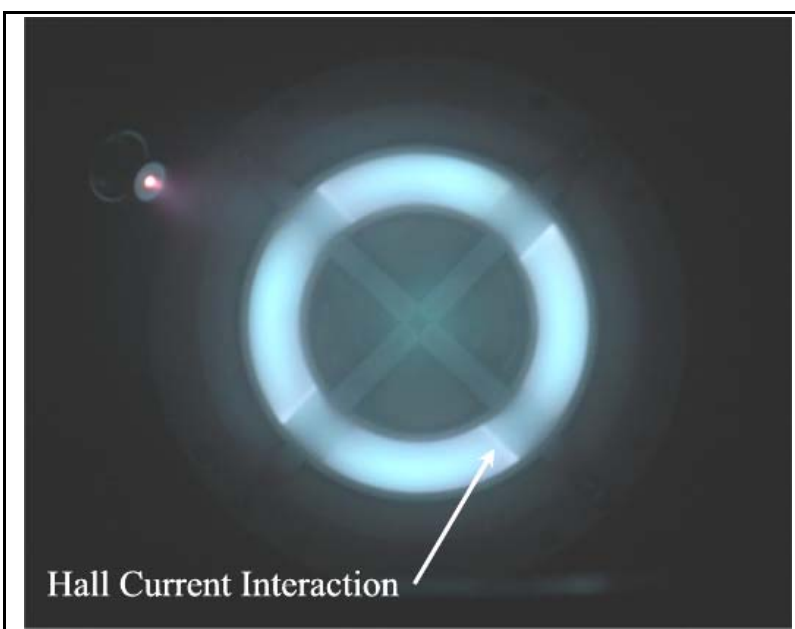

Figure 9: A photograph of the NASA-173GT operating in single-stage configuration that illustrates the interaction of the Hall current with the BN flux shunt shields. as a function of acceleration voltage was also considered for both single and two-stage. The thrust-to-acceleration power ratios also indicated no performance benefit of two-stage operation relative to single-stage. The potentially large electron leakage current and plume divergence may have negated any potential benefit of the two stage configuration relative to single stage.

\section{ExB Probe Results}

The NASA-173GT ion velocity distributions and ion species fractions for the thruster operating in single and two-stage configurations were obtained using an ExB probe. The ExB response as a function of acceleration potential for twostage thruster operation at 10

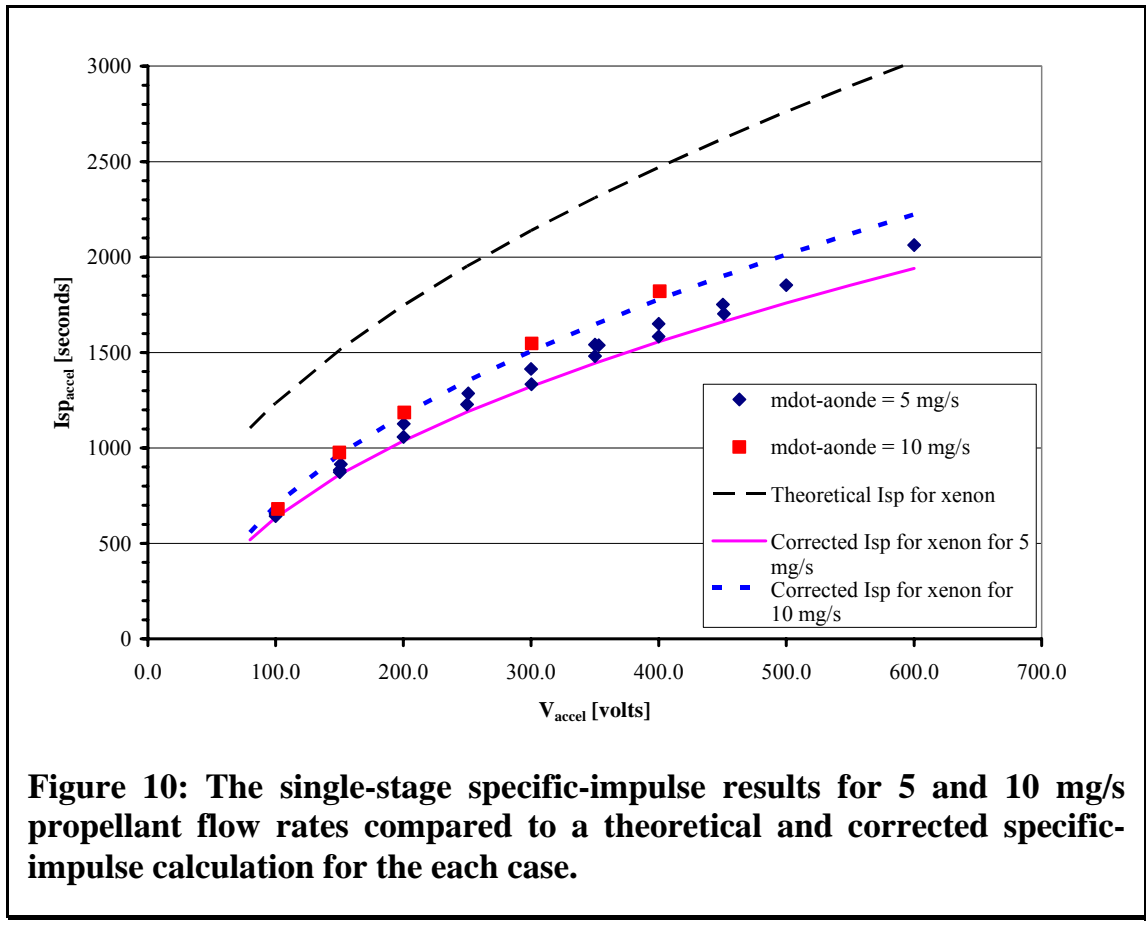
$\mathrm{mg} / \mathrm{s}$ and $15 \mathrm{~A}$ of ionization

current are illustrated in Figure 14. The primary $\mathrm{Xe}^{+}$peaks are separated by probe voltages of 16 and 13 volts. These voltages correspond to acceleration potentials of between 120 and 126 volts. The uncertainty in the ExB alignment was determined to be approximately $15 \%$ to $30 \%$ of the applied acceleration potentials. The lower limit was calculated based on unpublished ion thruster ExB measurements made with the same probe. The upper limit was determined from a comparison of the $\mathrm{Xe}^{+}$peaks for the 200, 300, and 400 volt traces shown in Figure 14.

The ExB probe traces for single and two-stage operation yielded distinct $\mathrm{Xe}^{+}$peaks with less distinct $\mathrm{Xe}^{++}$peaks. $\mathrm{Xe}^{+++}$peaks were not observed in the data gathered with the ExB probe, but were incorporated into the calculation of the ion species fractions. The ion species fraction calculated based on the ExB probe data are tabulated for both single and two-stage configurations in Table 3 of the Appendix. 
The ExB ion species fraction results indicated that increasing voltage increased the production of multiple charged ions. The increase of the multiple charged ions followed a similar trend exhibited by the NASA-173Mv2 [3] data for voltages between 200 and $500 \mathrm{~V}$. Operation of the NASA-173GT in a two-stage configuration did not reduce the amount of multiple charged ions. The increase in multiple ionized propellant with voltage indicated a $0.8 \%$ decrease of the charge utilization efficiency $\left(\eta_{\text {charge }}=\right.$ $98.4 \%$ to $97.6 \%$ ). The ability to operate the NASA-173GT at greater acceleration potentials may have shown a difference over SOA single-stage Hall thrusters.

\section{E. Gridded Faraday Probe Results}

The ion current density profiles of the NASA-173GT in single and two-stage configuration were measured with two gridded Faraday probes located $0.45 \mathrm{~m}$ and $0.95 \mathrm{~m}$ downstream of the thruster exit. The electron repelling grid was biased to $-30 \mathrm{~V}$ and the ion collector was biased to $+5 \mathrm{~V}$. These voltages were selected based on the measured background CEX floating potential. The divergence angles, total ion currents, and corrected total ion currents for single and two-stage configurations are presented in Table 4 of the Appendix. The divergence angles as a function of voltage and the ionization stage currents for the two-stage operation at a propellant flow rate of $10 \mathrm{mg} / \mathrm{s}$ are presented in Figure

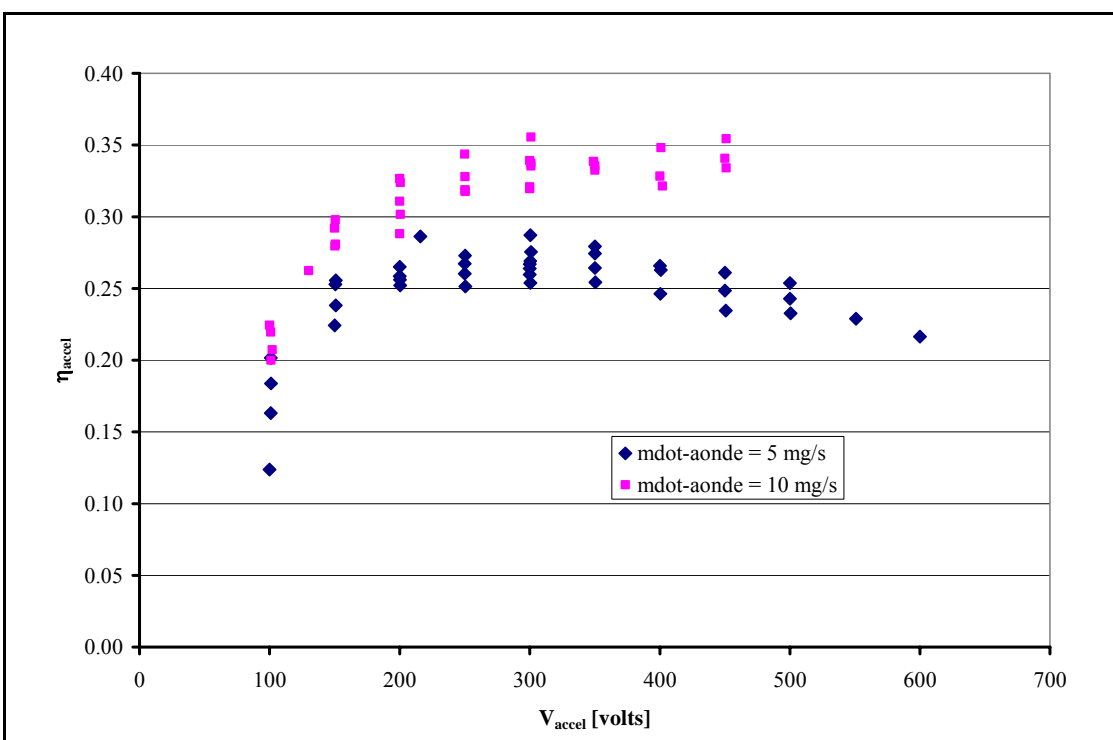

Figure 11: Two-stage anode efficiency as a function of acceleration potential for an anode flow rates of 5 and $10 \mathrm{mg} / \mathrm{s}$ and an ionization power level between 100 and 600 watts.

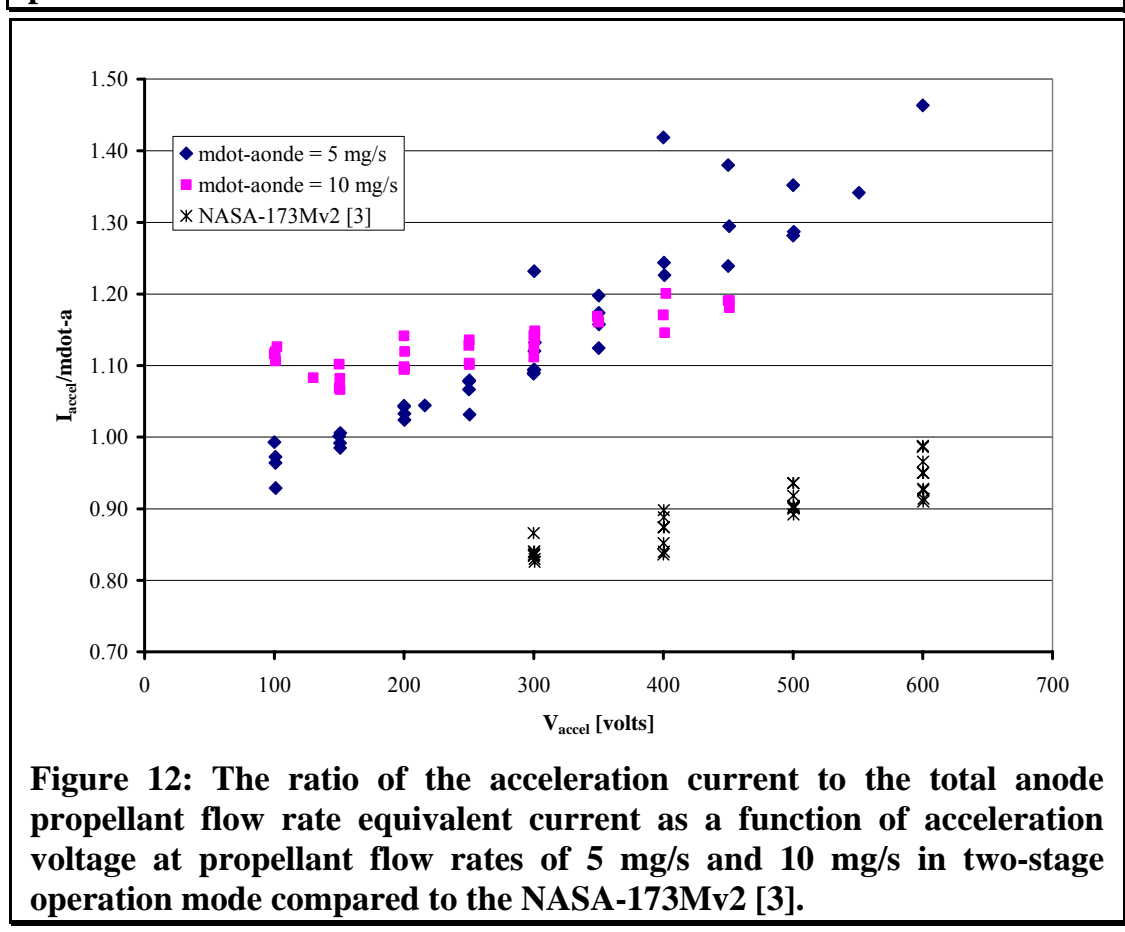

15. As acceleration voltage was increased the plume divergence decreased.

The two-stage plume divergence data at the acceleration potential of $400 \mathrm{~V}$, ionization stage current of $15 \mathrm{~A}$, and $10 \mathrm{mg} / \mathrm{s}$ propellant flow rate yielded the smallest half-angle of $39^{\circ}$ at $0.45 \mathrm{~m}$. The largest plume divergence occurred at $61^{\circ}$ for the $0.45 \mathrm{~m}$ probe at a 100 Volt acceleration potential, $10 \mathrm{mg} / \mathrm{s}$, and an ionization stage current of 15 A. The 0.45 and $0.95 \mathrm{~m}$ gridded Faraday probe data were separated by an average of $7^{\circ}$ at the same operating conditions. This difference was attributed to increased ion current measured at the $0.95 \mathrm{~m}$ probe location relative to the $0.45 \mathrm{~m}$ probe location as shown in Table 4 . The decrease in plume divergence with increasing voltage indicated a $156 \%$ increase of the plume divergence utilization efficiency $\left(\eta_{\beta}=23 \%\right.$ to $\left.60 \%\right)$.

The NASA-173GT results from the $0.45 \mathrm{~m}$ gridded Faraday probe were combined with the efficiency loss definitions [41] to estimate specific-impulse as a function of acceleration voltage for the NASA-173GT single and 
two-stage operation. The current utilization efficiency, the ratio of the ion beam current to the acceleration current, for both the single and two-stage data increased from $35 \%$ to $49 \%$ with voltage.

\section{Conclusion}

The NASA-173GT thruster was operated in single and twostage configurations. The single and two-stage thruster configuration provided approximately the same performance at each anode propellant flow rate studied. The performance and plasma plume results indicated that the NASA173GT operated with a large electron leakage current, $65 \%$ to $51 \%$ of the acceleration current, for both single and two-stage configurations. Physical observation of the thruster under operation and gridded Faraday probe results indicated that electron Hall current was intersecting the four flux shunts BN shields. The Hall current interaction with the flux shunts promoted an increase in the electron leakage mechanism. The ExB probe measurements indicated decreased charge utilization efficiency from $98.4 \%$ to $97.6 \%$ with increased voltage. The gridded Faraday probe measurements indicated increased plume divergence utilization efficiency from $23 \%$ to $60 \%$ with increased voltage. The electron leakage, the plume divergence, and the ion species fractions limited the anode efficiency of the thruster to a maximum of $34 \%$ to $36 \%$ for both the single and two-stage configurations. Possible future improvement to the NASA-173GT thruster design includes the removal of the flux shunts and shields that would improve the NASA173GT operation.

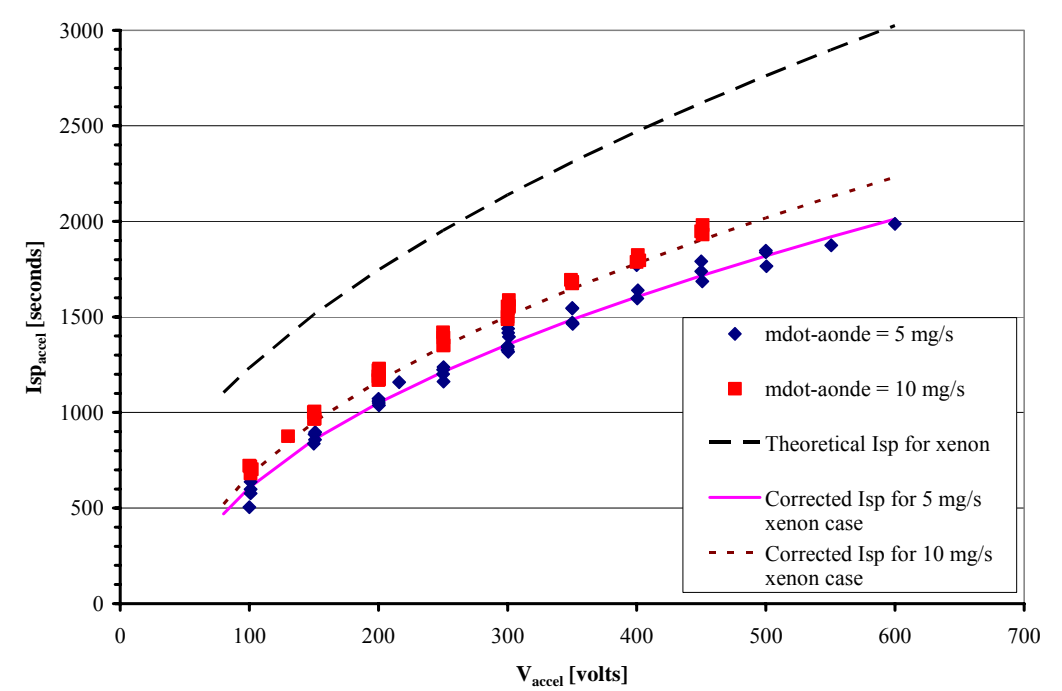

Figure 13: The two-stage specific-impulse results for 5 and $10 \mathrm{mg} / \mathrm{s}$ propellant flow rates compared to a theoretical and corrected specificimpulse calculation for each case.

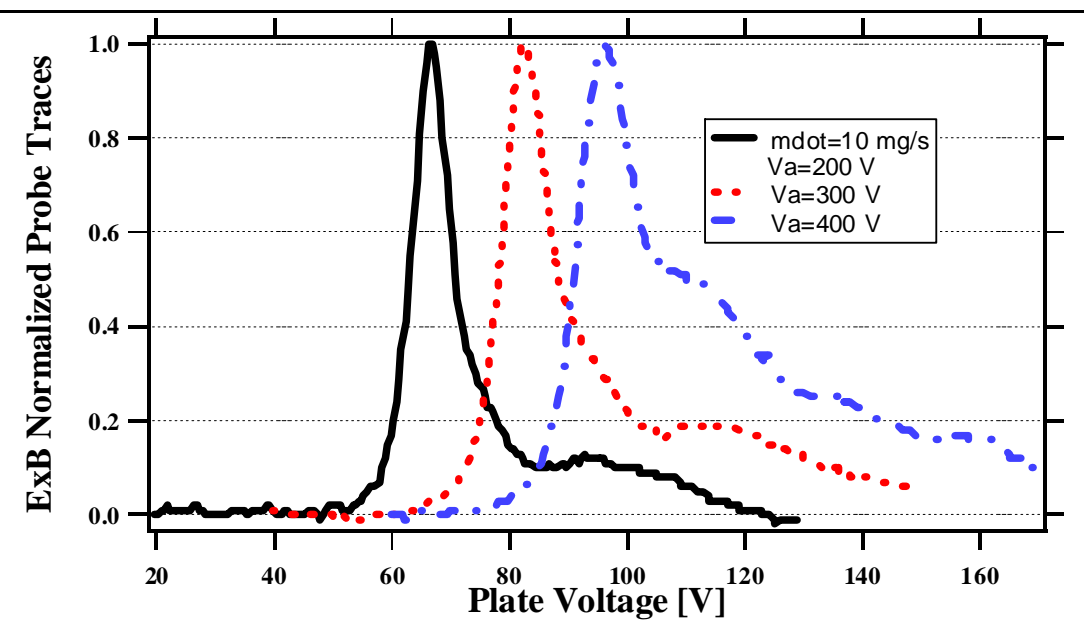

Figure 14: The two-stage ExB current traces of the NASA-173GT at 200,300 , and 400 volt acceleration potentials at $10 \mathrm{mg} / \mathrm{s}$ propellant flow rate and $15 \mathrm{~A}$ ionization stage current as a function of plate potential. 


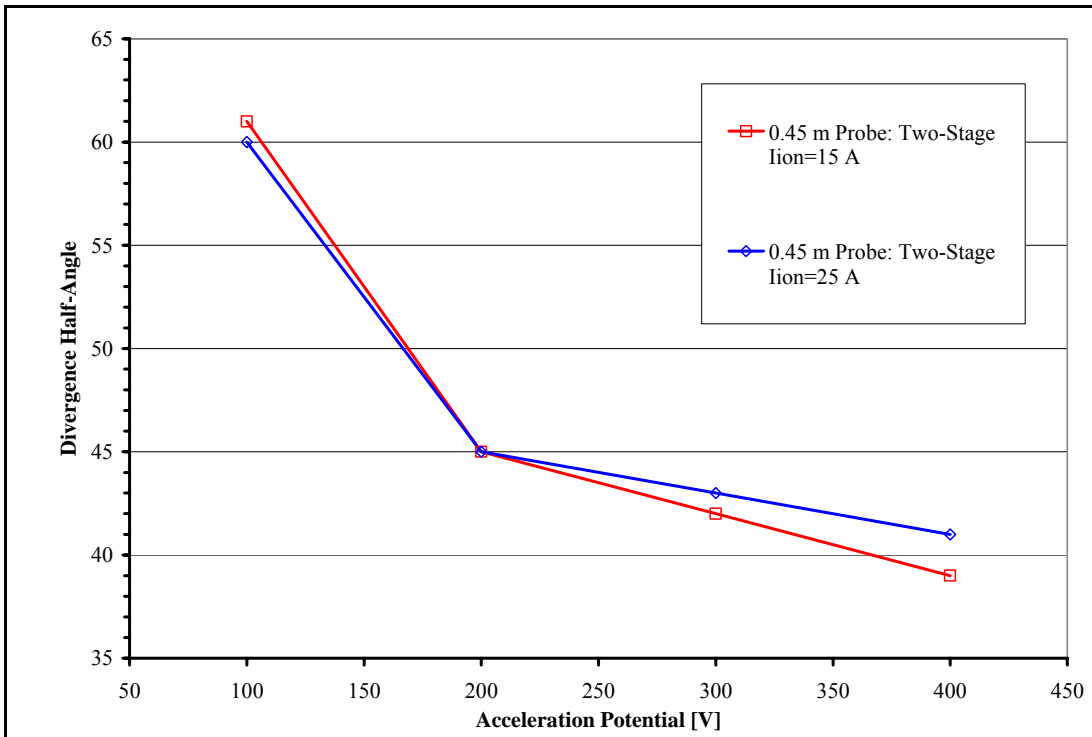

Figure 15: The divergence as a function of acceleration potential for 10 $\mathrm{mg} / \mathrm{s}$ propellant flow rate and ionization stage currents of 15 and $25 \mathrm{~A}$.

\section{Appendix}

Table 1: The single-stage performance characterization results of the NASA-173GT.

\begin{tabular}{|c|c|c|c|c|c|c|c|c|c|c|c|c|c|c|c|}
\hline $\mathrm{Va}[\mathrm{V}]$ & Ia $[\mathrm{A}]$ & $\begin{array}{c}\text { Accel } \\
\text { Power } \\
{[\mathrm{kW}]} \\
\end{array}$ & $\begin{array}{l}\text { Anode } \\
{[\mathrm{mg} / \mathrm{s}]}\end{array}$ & $\begin{array}{c}\text { Ion Cath } \\
{[\mathrm{mg} / \mathrm{s}]}\end{array}$ & $\begin{array}{c}\text { Hall Cath } \\
{[\mathrm{mg} / \mathrm{s}]}\end{array}$ & $\begin{array}{c}\text { Total Ion } \\
\text { Flow } \\
{[\mathrm{mg} / \mathrm{s}]} \\
\end{array}$ & Iin [A] & $\operatorname{Tin}[\mathrm{C}]$ & $\operatorname{Iom}[\mathrm{A}]$ & Tot [C] & $\mathrm{Vc}-\mathrm{g}[\mathrm{V}]$ & $\begin{array}{c}\text { Pressure } \\
\text { [Torr-Xe] }\end{array}$ & $\begin{array}{l}\text { Thrust } \\
{[\mathrm{mN}]}\end{array}$ & \begin{tabular}{|c|}
$\begin{array}{c}\text { Anode Isp } \\
\text { [sec] }\end{array}$ \\
\end{tabular} & $\begin{array}{c}\text { Anode } \\
\text { Eff }\end{array}$ \\
\hline 100.0 & 4.90 & 0.49 & 4.70 & 0.00 & 0.50 & 4.70 & 1.21 & 30 & 1.00 & 30 & -9.1 & $2.6 \mathrm{E}-06$ & 30.2 & 655 & 0.20 \\
\hline 100.0 & 5.20 & 0.52 & 4.96 & 0.00 & 0.50 & 4.96 & 1.21 & 32 & 1.00 & 30 & -8.9 & 2.7E-06 & 31.3 & 643 & 0.19 \\
\hline 150.3 & 5.03 & 0.76 & 4.92 & 0.00 & 0.50 & 4.92 & 1.88 & 39 & 2.22 & 36 & -11.0 & $2.7 \mathrm{E}-06$ & 42.7 & 885 & 0.24 \\
\hline 150.3 & 5.11 & 0.77 & 4.98 & 0.00 & 0.50 & 4.98 & 1.89 & 43 & 2.22 & 40 & -11.0 & $2.7 \mathrm{E}-06$ & 42.7 & 873 & 0.24 \\
\hline 250.0 & 5.16 & 1.29 & 4.85 & 0.00 & 0.50 & 4.85 & 3.88 & 79 & 3.96 & 66 & -12.6 & 2.7E-06 & 58.4 & 1228 & 0.27 \\
\hline 300.3 & 5.29 & 1.59 & 4.94 & 0.00 & 0.50 & 4.94 & 3.80 & 113 & 3.93 & 91 & -12.0 & $2.6 \mathrm{E}-06$ & 64.6 & 1335 & 0.27 \\
\hline 350.0 & 5.49 & 1.92 & 4.96 & 0.00 & 0.50 & 4.96 & 3.84 & 221 & 3.72 & 151 & -11.5 & $2.7 \mathrm{E}-06$ & 72.0 & 1481 & 0.27 \\
\hline 400.0 & 5.54 & 2.22 & 4.98 & 0.00 & 0.50 & 4.98 & 4.90 & 335 & 4.35 & 210 & -11.5 & 2.7E-06 & 77.4 & 1583 & 0.27 \\
\hline 250.8 & 5.35 & 1.34 & 2.98 & 2.00 & 0.50 & 4.98 & 3.60 & 54 & 3.60 & 45 & -12.4 & $2.6 \mathrm{E}-06$ & 62.9 & 1286 & 0.30 \\
\hline 300.0 & 5.45 & 1.64 & 2.98 & 2.00 & 0.50 & 4.98 & 3.46 & 70 & 3.99 & 59 & -12.0 & 2.6E-06 & 69.1 & 1414 & 0.29 \\
\hline 350.0 & 5.55 & 1.94 & 2.98 & 2.00 & 0.50 & 4.98 & 3.80 & 90 & 4.30 & 76 & -12.3 & 2.7E-06 & 75.4 & 1542 & 0.29 \\
\hline 353.0 & 5.58 & 1.97 & 2.98 & 2.00 & 0.50 & 4.98 & 3.70 & 133 & 4.11 & 103 & -11.0 & $2.7 \mathrm{E}-06$ & 75.2 & 1538 & 0.29 \\
\hline 400.0 & 5.66 & 2.26 & 2.98 & 2.00 & 0.50 & 4.98 & 4.60 & 171 & 4.85 & 130 & -11.4 & $2.6 \mathrm{E}-06$ & 80.7 & 1651 & 0.29 \\
\hline 450.4 & 5.84 & 2.63 & 2.98 & 2.00 & 0.50 & 4.98 & 5.08 & 235 & 4.90 & 168 & -11.2 & $2.6 \mathrm{E}-06$ & 85.6 & 1752 & 0.28 \\
\hline 500.0 & 6.09 & 3.05 & 2.98 & 2.00 & 0.50 & 4.98 & 4.96 & 302 & 4.86 & 200 & -10.5 & $2.6 \mathrm{E}-06$ & 90.6 & 1853 & 0.27 \\
\hline 600.0 & 6.65 & 3.99 & 2.98 & 2.00 & 0.50 & 4.98 & 5.80 & 370 & 4.40 & 223 & -9.6 & $2.6 \mathrm{E}-06$ & 100.9 & 2063 & 0.26 \\
\hline
\end{tabular}


Table 2: The two-stage performance characterization results of the NASA-173GT.

\begin{tabular}{|c|c|c|c|c|c|c|c|c|c|c|c|c|c|c|c|c|c|c|}
\hline $\begin{array}{r}\mathrm{Va} \\
{[\mathrm{V}]} \\
\end{array}$ & $\begin{array}{c}\text { Ia } \\
{[\mathrm{A}]}\end{array}$ & $\begin{array}{c}\mathrm{Id} \\
{[\mathrm{A}]}\end{array}$ & $\begin{array}{c}\text { Acce } \\
1 \\
\text { Powe } \\
r \\
{[\mathrm{~kW}]}\end{array}$ & $\begin{array}{l}\text { Ion } \\
\text { Powe } \\
\text { r [W] }\end{array}$ & $\begin{array}{c}\text { Anod } \\
\mathrm{e} \\
{[\mathrm{mg} /} \\
\mathrm{s}]\end{array}$ & $\begin{array}{c}\text { Ion } \\
\text { Cath } \\
{[\mathrm{mg} /} \\
\mathrm{s}]\end{array}$ & $\begin{array}{l}\text { Hall } \\
\text { Cath } \\
{[\mathrm{mg} /} \\
\mathrm{s}]\end{array}$ & $\begin{array}{c}\text { Total } \\
\text { Ion } \\
\text { Flow } \\
{[\mathrm{mg} /} \\
\mathrm{s}]\end{array}$ & $\begin{array}{l}\text { Iin } \\
{[\mathrm{A}]}\end{array}$ & $\begin{array}{l}\text { Iot } \\
{[\mathrm{A}]}\end{array}$ & $\begin{array}{l}\text { Idc1 } \\
{[\mathrm{A}]}\end{array}$ & $\begin{array}{l}\mathrm{Idc} 2 \\
{[\mathrm{~A}]}\end{array}$ & $\begin{array}{l}\text { Idc3- } \\
4[\mathrm{~A}]\end{array}$ & $\begin{array}{l}\mathrm{Idc5} \\
{[\mathrm{A}]}\end{array}$ & $\begin{array}{l}\mathrm{Vc}-\mathrm{g} \\
{[\mathrm{V}]}\end{array}$ & $\begin{array}{c}\text { Thru } \\
\text { st } \\
{[\mathrm{mN}]}\end{array}$ & $\begin{array}{l}\text { Anod } \\
\text { e Isp } \\
\text { [sec] }\end{array}$ & $\begin{array}{l}\text { Anod } \\
\text { e Eff }\end{array}$ \\
\hline 100.9 & 4.91 & 15.09 & 0.50 & 227 & 4.06 & 0.99 & 0.50 & 5.05 & 1.43 & 1.58 & $\begin{array}{l}1.27 \\
\end{array}$ & 2.90 & 2.98 & 3.49 & -10.5 & 28.6 & 577 & 0.16 \\
\hline 150.9 & 4.97 & 15.09 & 0.75 & 229 & 3.95 & 0.99 & 0.50 & 4.94 & 1.37 & 1.52 & 1.16 & 3.05 & 3.03 & 3.38 & -10.8 & 43.5 & 898 & 0.26 \\
\hline 200.0 & 5.13 & 15.11 & 1.03 & 237 & 3.93 & $\begin{array}{l}0.99 \\
\end{array}$ & 0.50 & 4.92 & 1.83 & 1.77 & 1.07 & $\begin{array}{l}2.99 \\
\end{array}$ & 2.50 & 2.96 & -11.2 & 51.7 & 1072 & 0.27 \\
\hline 250.3 & 5.31 & 15.12 & 1.33 & 236 & 3.93 & 0.99 & 0.50 & 4.92 & 2.46 & 2.43 & 0.95 & 3.19 & 2.69 & 3.35 & $\begin{array}{l}-11.6 \\
\end{array}$ & 59.7 & 1238 & 0.27 \\
\hline 300.4 & 6.06 & 15.12 & 1.82 & 236 & 3.93 & $\begin{array}{l}0.99 \\
\end{array}$ & 0.50 & 4.92 & 2.18 & 2.25 & 0.96 & 3.30 & 2.69 & 3.32 & -10.5 & 69.4 & 1439 & 0.27 \\
\hline 100.9 & 4.93 & 20.00 & 0.50 & 306 & 4.12 & 0.99 & 0.50 & 5.11 & 1.14 & 1.30 & 0.90 & 2.90 & 2.30 & 3.00 & -9.7 & 32.0 & 638 & 0.20 \\
\hline $\begin{array}{l}150.6 \\
\end{array}$ & 4.90 & 20.00 & $\begin{array}{l}0.74 \\
\end{array}$ & 300 & 3.95 & $\begin{array}{l}0.99 \\
\end{array}$ & $\begin{array}{l}0.50 \\
\end{array}$ & \begin{tabular}{|l|l|}
4.94 \\
\end{tabular} & 1.22 & 1.33 & 0.99 & $\begin{array}{l}2.19 \\
\end{array}$ & 2.32 & 3.10 & -10.0 & $\begin{array}{r}42.9 \\
\end{array}$ & $\begin{array}{l}886 \\
\end{array}$ & 0.25 \\
\hline 200.3 & 5.08 & 20.00 & 1.02 & 310 & 3.93 & 0.99 & 0.50 & 4.92 & 1.74 & 1.90 & $\begin{array}{l}0.87 \\
\end{array}$ & 2.38 & 2.20 & 3.81 & -10.7 & 50.6 & 1049 & 0.26 \\
\hline 250.0 & 5.27 & 20.00 & 1.32 & 320 & 3.95 & 0.99 & 0.50 & 4.94 & 2.42 & 2.44 & 0.85 & 2.80 & 2.00 & $\begin{array}{l}3.37 \\
\end{array}$ & -11.2 & 58.2 & 1201 & 0.26 \\
\hline 299.9 & 5.38 & 20.10 & 1.61 & 322 & 3.95 & 0.99 & 0.50 & 4.94 & 2.74 & 2.83 & 0.83 & 2.75 & 2.10 & 3.48 & -10.6 & 64.3 & 1327 & 0.26 \\
\hline 101.0 & 4.65 & 25.00 & 0.47 & 390 & 4.01 & 0.99 & 0.50 & 5.01 & 1.31 & 1.22 & 1.27 & 2.70 & 2.30 & 2.60 & -9.5 & 29.4 & 599 & 0.18 \\
\hline 150.8 & 4.91 & 25.00 & 0.74 & 390 & 3.99 & $\begin{array}{ll}0.99 \\
\end{array}$ & 0.50 & 4.98 & 1.34 & 1.40 & 0.87 & 2.72 & 2.50 & 2.88 & -10.0 & 41.9 & 858 & 0.24 \\
\hline 200.4 & 5.06 & 25.00 & 1.01 & 393 & 3.95 & 0.99 & 0.50 & 4.94 & 1.19 & 1.44 & 0.89 & 2.78 & 2.20 & 3.20 & -9.5 & 50.3 & 1037 & 0.25 \\
\hline 250.5 & 5.12 & 25.00 & 1.28 & 400 & 3.97 & 0.99 & 0.50 & 4.96 & 1.21 & 1.36 & 1.06 & 2.73 & 1.87 & 3.38 & -9.5 & 56.6 & 1162 & 0.25 \\
\hline 300.5 & 5.43 & 25.00 & 1.63 & 400 & 3.97 & \begin{tabular}{|c|}
0.99 \\
\end{tabular} & 0.50 & \begin{tabular}{|l|l|}
4.96 \\
\end{tabular} & 2.06 & 2.01 & 0.84 & \begin{tabular}{|l|l|}
2.91 \\
\end{tabular} & $\begin{array}{l}2.32 \\
\end{array}$ & 3.06 & -10.0 & $\begin{array}{l}64.1 \\
\end{array}$ & 1317 & 0.25 \\
\hline 216.0 & 5.34 & 15.10 & 1.15 & 252 & 3.11 & 2.00 & 0.50 & 5.11 & 1.55 & 1.67 & 0.83 & 2.95 & 2.65 & 2.06 & -11.0 & 58.1 & 1159 & 0.29 \\
\hline 300.5 & 5.56 & 15.10 & 1.67 & 251 & 2.96 & 2.00 & 0.50 & 4.96 & 1.76 & 1.99 & 0.81 & 2.94 & 2.66 & 2.75 & $\begin{array}{l}-10.6 \\
\end{array}$ & 69.0 & 1418 & $\begin{array}{l}0.29 \\
\end{array}$ \\
\hline 350.0 & 5.80 & 15.10 & 2.03 & 248 & 2.94 & 2.00 & 0.50 & 4.94 & 2.36 & 2.56 & 1.39 & 2.88 & 2.64 & 2.99 & -10.0 & $\begin{array}{l}74.8 \\
\end{array}$ & 1544 & 0.28 \\
\hline 400.8 & 6.06 & 15.10 & 2.43 & 251 & 2.94 & 2.00 & $\begin{array}{l}0.50 \\
\end{array}$ & \begin{tabular}{|l|l|}
4.94 \\
\end{tabular} & 3.15 & 3.54 & 0.50 & \begin{tabular}{|l|l}
2.80 \\
\end{tabular} & 2.64 & \begin{tabular}{|l|l|}
2.98 \\
\end{tabular} & -10.0 & 79.4 & 1639 & 0.26 \\
\hline 450.0 & 6.15 & 15.10 & 2.77 & 246 & 2.96 & 2.00 & 0.50 & $\begin{array}{l}4.96 \\
\end{array}$ & 4.07 & 4.30 & 0.63 & 2.00 & \begin{tabular}{|l|l}
2.99 \\
\end{tabular} & $\begin{array}{l}2.98 \\
\end{array}$ & -10.3 & 84.7 & 1739 & 0.26 \\
\hline 500.0 & 6.36 & 15.10 & 3.18 & 244 & 2.96 & 2.00 & 0.50 & 4.96 & 4.67 & 4.67 & 0.63 & 3.00 & 2.99 & 2.98 & -10.8 & 89.5 & 1838 & 0.25 \\
\hline 301.0 & 5.62 & 20.00 & 1.69 & 540 & 2.96 & 2.00 & 0.50 & $\begin{array}{l}4.96 \\
\end{array}$ & 2.11 & 2.07 & 0.71 & 3.00 & 3.00 & 3.00 & -11.5 & 68.0 & 1397 & 0.28 \\
\hline 350.0 & 5.97 & 20.00 & 2.09 & 560 & 2.98 & 2.00 & 0.50 & $\begin{array}{l}4.98 \\
\end{array}$ & 2.25 & 2.35 & 0.71 & 2.90 & 2.88 & 3.00 & -10.5 & 75.6 & 1546 & 0.27 \\
\hline 400.0 & 6.98 & 20.00 & 2.79 & 600 & 2.92 & 2.00 & 0.50 & 4.92 & 3.03 & 3.40 & 0.58 & 2.90 & 2.88 & 3.00 & -9.8 & 85.5 & 1771 & 0.27 \\
\hline 450.0 & 6.82 & 20.00 & 3.07 & 500 & 2.94 & 2.00 & 0.50 & 4.94 & 3.26 & 3.50 & $\begin{array}{l}0.82 \\
\end{array}$ & 2.90 & 2.88 & 3.00 & -9.9 & 86.8 & 1791 & 0.25 \\
\hline 500.0 & 6.68 & 20.00 & 3.34 & 340 & 2.94 & 2.00 & 0.50 & 4.94 & 3.80 & 3.87 & 0.82 & 2.90 & 2.88 & 3.00 & -9.9 & 89.5 & 1847 & $\begin{array}{l}0.24 \\
\end{array}$ \\
\hline 300.0 & 5.43 & 25.10 & 1.63 & 432 & 2.96 & 2.00 & 0.50 & 4.96 & 1.50 & 1.78 & 0.88 & 3.20 & 3.00 & 3.00 & -10.7 & 65.3 & 1342 & 0.26 \\
\hline 350.3 & 5.72 & 25.10 & 2.00 & 439 & 2.94 & 2.00 & 0.50 & 4.94 & 2.23 & 2.45 & 0.73 & 3.15 & 3.00 & 3.20 & -10.7 & 71.0 & 1464 & 0.25 \\
\hline 400.4 & 6.12 & 25.10 & 2.45 & 444 & 2.92 & 2.00 & 0.50 & 4.92 & 2.54 & 2.64 & 0.66 & 3.15 & 3.00 & 3.20 & -9.9 & 77.1 & 1597 & 0.25 \\
\hline 450.7 & 6.37 & 25.10 & 2.87 & 449 & 2.92 & 2.00 & 0.50 & $\begin{array}{l}4.92 \\
\end{array}$ & 3.00 & 3.25 & 0.45 & 2.95 & 2.90 & 3.20 & -9.6 & 81.4 & 1686 & 0.23 \\
\hline 500.5 & 6.36 & 25.10 & 3.18 & 459 & 2.94 & 2.00 & 0.50 & 4.94 & 3.90 & 3.97 & 0.47 & 2.95 & 2.90 & 3.18 & -10.0 & 85.6 & 1765 & $\begin{array}{l}0.23 \\
\end{array}$ \\
\hline 550.7 & 6.60 & 25.10 & 3.63 & 462 & 2.92 & 2.00 & 0.50 & 4.92 & 4.30 & 4.04 & 0.47 & 2.95 & 2.90 & 3.18 & -9.7 & 90.5 & 1875 & 0.23 \\
\hline 600.0 & 7.20 & 25.10 & 4.32 & 462 & 2.92 & 2.00 & 0.50 & 4.92 & 4.00 & 4.00 & 0.47 & 2.95 & 2.90 & 3.18 & -8.7 & 95.9 & 1987 & 0.22 \\
\hline 100.0 & 4.95 & 15.00 & 0.50 & 234 & 2.98 & 2.00 & 0.50 & 4.98 & 2.00 & 2.32 & $\begin{array}{l}0.47 \\
\end{array}$ & 2.60 & 3.00 & 1.94 & -10.4 & 24.7 & 505 & 0.12 \\
\hline 150.0 & 4.97 & 15.00 & 0.75 & 234 & 2.96 & 2.00 & 0.50 & 4.96 & 2.60 & 2.75 & 0.54 & 2.80 & 2.98 & 1.74 & -12.2 & 40.7 & 837 & 0.22 \\
\hline 200.0 & 5.18 & 15.00 & 1.04 & 240 & 2.96 & 2.00 & 0.50 & 4.96 & 2.86 & 3.13 & 0.44 & 2.93 & 2.50 & 1.60 & -12.0 & 51.6 & 1059 & 0.26 \\
\hline 250.0 & 5.35 & 15.00 & 1.34 & 240 & 2.96 & 2.00 & 0.50 & 4.96 & 2.97 & 3.50 & 0.23 & 2.67 & 2.70 & 1.56 & -12.0 & 59.6 & 1224 & 0.27 \\
\hline 300.0 & 5.41 & 15.00 & 1.62 & 240 & 2.96 & 2.00 & 0.50 & 4.96 & 3.70 & 3.92 & 0.43 & 2.63 & 2.50 & 1.93 & -11.4 & 65.6 & 1347 & $\begin{array}{l}0.27 \\
\end{array}$ \\
\hline 350.0 & 5.58 & 15.00 & 1.95 & 236 & 2.96 & 2.00 & 0.50 & 4.96 & 4.10 & 4.00 & 0.34 & 2.77 & 2.50 & 2.10 & -11.2 & 71.6 & 1470 & 0.26 \\
\hline 100.0 & $\begin{array}{l}11.30 \\
\end{array}$ & 15.00 & 1.13 & 198 & 8.12 & 2.00 & 1.00 & 10.12 & 1.30 & 1.30 & $\begin{array}{l}1.18 \\
\end{array}$ & \begin{tabular}{|l|l|}
2.90 \\
\end{tabular} & $\begin{array}{l}3.15 \\
\end{array}$ & 3.14 & $\begin{array}{r}-6.7 \\
\end{array}$ & $\begin{array}{l}71.7 \\
\end{array}$ & 722 & 0.22 \\
\hline 150.0 & 11.20 & 15.00 & 1.68 & 206 & 8.16 & 2.00 & 1.00 & 10.17 & 1.90 & 1.97 & 1.14 & 3.00 & 3.12 & 3.17 & -8.2 & 99.9 & 1002 & 0.29 \\
\hline 200.5 & 11.36 & 15.00 & 2.28 & 211 & 8.14 & 2.00 & 1.00 & 10.14 & 2.64 & 2.86 & 1.10 & 3.08 & 3.07 & 3.50 & -9.1 & 122.3 & 1229 & 0.32 \\
\hline 250.3 & 11.35 & 15.00 & 2.84 & 215 & 7.99 & 2.00 & 1.00 & 9.99 & 3.36 & 3.48 & 1.14 & 2.90 & 3.06 & 3.20 & -9.7 & 136.5 & 1392 & 0.33 \\
\hline 300.0 & 11.34 & 15.00 & 3.40 & 218 & 7.93 & 2.00 & 1.00 & 9.93 & 4.07 & 4.17 & 1.13 & 2.90 & 3.06 & 3.30 & -9.9 & 151.4 & 1554 & 0.34 \\
\hline $\begin{array}{l}100.8 \\
\end{array}$ & 11.03 & 20.00 & $\begin{array}{l}1.11 \\
\end{array}$ & 285 & $\begin{array}{l}7.86 \\
\end{array}$ & 1.99 & 1.00 & $\begin{array}{l}9.86 \\
\end{array}$ & 1.44 & 1.51 & 1.00 & $\begin{array}{l}2.54 \\
\end{array}$ & $\begin{array}{l}2.90 \\
\end{array}$ & $\begin{array}{l}3.15 \\
\end{array}$ & $\begin{array}{l}-7.0 \\
\end{array}$ & $\begin{array}{l}69.4 \\
\end{array}$ & 717 & 0.22 \\
\hline 150.6 & 10.85 & 20.00 & 1.63 & 282 & 8.03 & 1.99 & 1.00 & 10.03 & 2.10 & 2.21 & 0.82 & 2.82 & 3.23 & 2.89 & -8.6 & 98.8 & 1004 & 0.30 \\
\hline 200.0 & 10.95 & 20.00 & 2.19 & 288 & 8.01 & 1.99 & 1.00 & 10.01 & 3.16 & 3.46 & 0.83 & 2.58 & 2.63 & 2.83 & -9.7 & 116.7 & 1189 & 0.31 \\
\hline 250.3 & 11.02 & 20.00 & 2.76 & 280 & 8.01 & 1.99 & 1.00 & 10.01 & 3.69 & 3.95 & 0.50 & 2.70 & 2.50 & 2.64 & -10.0 & 132.7 & 1352 & 0.32 \\
\hline 300.0 & $\begin{array}{l}11.27 \\
\end{array}$ & 20.00 & $\begin{array}{l}3.38 \\
\end{array}$ & 290 & 8.01 & $\begin{array}{l}1.99 \\
\end{array}$ & 1.00 & 10.01 & 4.28 & 4.13 & 0.98 & \begin{tabular}{|l|l}
2.70 \\
\end{tabular} & $\begin{array}{l}2.50 \\
\end{array}$ & \begin{tabular}{|l|}
2.71 \\
\end{tabular} & -10.0 & 147.3 & 1501 & 0.32 \\
\hline 102.0 & 11.40 & 25.00 & 1.16 & 358 & 8.12 & 2.00 & 1.00 & 10.12 & 1.35 & 1.32 & 0.91 & 2.43 & 2.99 & 3.20 & -7.0 & 69.8 & 703 & 0.21 \\
\hline 150.7 & 10.68 & 25.00 & 1.61 & 366 & 8.01 & 2.00 & 1.00 & 10.02 & 2.53 & 2.35 & 0.70 & 2.70 & 2.70 & 2.86 & -9.1 & 95.1 & 968 & 0.28 \\
\hline 200.5 & 10.90 & 25.00 & 2.19 & 374 & 7.95 & 2.00 & 1.00 & 9.95 & 3.06 & 3.13 & 0.66 & 2.63 & 2.84 & 2.82 & -9.6 & 114.5 & 1173 & 0.30 \\
\hline 250.4 & 11.00 & 25.00 & 2.75 & 384 & 7.97 & 2.00 & 1.00 & \begin{tabular}{|l|l}
9.97 \\
\end{tabular} & 3.58 & 3.69 & 0.76 & $\begin{array}{l}2.72 \\
\end{array}$ & 2.84 & 2.82 & \begin{tabular}{|l|l}
-9.8 \\
\end{tabular} & 132.1 & 1350 & 0.32 \\
\hline 300.0 & 11.16 & 25.00 & 3.35 & 394 & 8.03 & 2.00 & 1.00 & 10.04 & 4.45 & 4.41 & 0.76 & 2.72 & 2.84 & 2.82 & -10.0 & 146.5 & 1488 & 0.32 \\
\hline 101.0 & 11.00 & 25.00 & 1.11 & 345 & 6.94 & 3.01 & 1.00 & 9.94 & 1.23 & 1.42 & 1.11 & 2.88 & 2.70 & 2.67 & -6.8 & 66.5 & 682 & 0.20 \\
\hline 150.2 & 10.67 & 25.00 & 1.60 & 360 & 6.98 & 3.01 & 1.00 & 9.98 & 1.78 & 1.84 & 0.84 & 2.74 & 2.67 & 2.52 & $\begin{array}{l}-7.9 \\
\end{array}$ & 94.6 & 966 & 0.28 \\
\hline 200.0 & 11.20 & 25.00 & 2.24 & 367 & 6.81 & 3.01 & 1.00 & \begin{tabular}{|c|}
9.81 \\
\end{tabular} & 2.35 & 2.35 & 0.89 & 2.68 & 2.78 & 2.90 & -8.0 & 112.6 & 1170 & $\begin{array}{r}0.29 \\
\end{array}$ \\
\hline 200.0 & 11.00 & 15.00 & 2.20 & 237 & 8.01 & 2.00 & 1.00 & 10.02 & 3.00 & 3.20 & 0.64 & 2.95 & 2.90 & 3.00 & -10.3 & 120.0 & 1221 & 0.33 \\
\hline 250.0 & 11.25 & 15.00 & 2.81 & 236 & 7.97 & 2.00 & 1.00 & 9.97 & 3.60 & 3.70 & 0.65 & 3.00 & 2.90 & 3.00 & -10.1 & 138.8 & 1419 & 0.34 \\
\hline 301.0 & 11.30 & 15.00 & 3.40 & 239 & 7.95 & 2.00 & 1.00 & 9.95 & 3.88 & 3.88 & 0.65 & 3.00 & 2.90 & 3.00 & -10.5 & 155.1 & 1589 & 0.36 \\
\hline 349.0 & 11.68 & 15.00 & 4.08 & 245 & 7.99 & 2.00 & 1.00 & 9.99 & 4.68 & 4.99 & 0.65 & 3.00 & 2.90 & 3.00 & -10.6 & 166.1 & 1694 & 0.34 \\
\hline 401.0 & 11.45 & 15.00 & $\begin{array}{l}4.59 \\
\end{array}$ & 254 & $\begin{array}{l}7.99 \\
\end{array}$ & 2.00 & 1.00 & \begin{tabular}{|c|}
9.99 \\
\end{tabular} & 4.35 & 4.58 & 0.64 & 3.00 & 2.90 & 3.00 & -10.8 & 178.8 & 1823 & 0.35 \\
\hline 451.0 & 11.80 & 15.00 & 5.32 & 237 & 7.99 & 2.00 & 1.00 & 9.99 & 4.80 & 4.40 & 0.64 & 3.00 & 2.90 & 3.00 & -10.4 & 194.2 & 1981 & 0.35 \\
\hline 130.0 & 10.80 & 20.00 & 1.40 & 300 & 7.97 & 2.00 & 1.00 & 9.97 & 1.86 & 1.99 & 0.60 & 3.00 & 3.00 & 3.00 & -9.0 & 85.7 & 876 & 0.26 \\
\hline 301.0 & 11.40 & 20.00 & 3.43 & 314 & 7.93 & 2.00 & 1.00 & 9.93 & 3.60 & 3.80 & 0.65 & 3.00 & 2.90 & 3.00 & -9.8 & 151.6 & 1557 & 0.34 \\
\hline 350.0 & 11.60 & 20.00 & 4.06 & 320 & 7.99 & 2.00 & 1.00 & \begin{tabular}{|l|l|}
9.99 \\
\end{tabular} & 4.44 & 4.70 & 0.65 & 3.00 & 2.90 & 3.00 & -10.5 & 164.3 & 1676 & 0.33 \\
\hline 402.0 & 12.00 & 20.00 & 4.82 & 320 & 7.99 & 2.00 & 1.00 & \begin{tabular}{|c|}
9.99 \\
\end{tabular} & 4.99 & 5.00 & 0.58 & 2.98 & 2.84 & 2.96 & $\begin{array}{l}-9.9 \\
\end{array}$ & 176.1 & 17796 & 0.32 \\
\hline 451.0 & 11.90 & 20.00 & 5.37 & 326 & 7.99 & 2.00 & 1.00 & 9.99 & 5.60 & 5.00 & 0.58 & 2.98 & 2.84 & 2.96 & -10.0 & 189.3 & 1931 & 0.33 \\
\hline 301.0 & 11.50 & 25.10 & 3.46 & 412 & 8.01 & 2.00 & 1.00 & 10.02 & 3.95 & 4.13 & 0.60 & 2.98 & 2.80 & 2.97 & -10.1 & 152.5 & 1552 & 0.34 \\
\hline 350.0 & 11.58 & 25.10 & 4.05 & 419 & 7.97 & 2.00 & 1.00 & 9.97 & 4.15 & 4.35 & 0.65 & 2.98 & 2.80 & 2.97 & -10.2 & 164.7 & 1683 & 0.34 \\
\hline 400.0 & 11.70 & 25.10 & 4.68 & 424 & 7.99 & 2.00 & 1.00 & 9.99 & 4.67 & 4.81 & 0.65 & 2.98 & 2.80 & 2.97 & -10.0 & 175.3 & 1788 & 0.33 \\
\hline 450.0 & 11.90 & 25.10 & 5.36 & 422 & 7.99 & 2.00 & 1.00 & 9.99 & 4.96 & 4.87 & 0.65 & 2.98 & 2.80 & 2.97 & -9.5 & 191.0 & 1948 & 0.34 \\
\hline
\end{tabular}


Table 3: The ion species fractions results for the NASA-173GT in both single and two-stage configurations.

\begin{tabular}{|c|c|c|c|c|c|c|c|c|}
\hline $\begin{array}{c}\text { Thruster } \\
\text { Configuration }\end{array}$ & $\begin{array}{l}\mathrm{V}_{\text {accel }} \\
{[\mathrm{V}]}\end{array}$ & $\begin{array}{l}\mathrm{I}_{\text {ion }} \\
{[\mathrm{A}]}\end{array}$ & $\begin{array}{c}\dot{m}_{\text {anode }} \\
{[\mathrm{mg} / \mathrm{s}]}\end{array}$ & $\zeta_{\mathrm{Xe}}^{+}$ & $\zeta_{\mathrm{xe}}{ }^{++}$ & $\zeta_{\mathrm{Xe}}{ }^{+++}$ & $\begin{array}{l}\phi_{\mathrm{Xe}}^{+} \\
{[\mathrm{V}]}\end{array}$ & $\Delta \mathrm{V}_{\text {accel- } \phi}$ \\
\hline \multirow[t]{3}{*}{ Single-Stage } & 200 & - & 10 & $96.3 \%$ & $3.2 \%$ & $0.5 \%$ & 230 & $+15.0 \%$ \\
\hline & 300 & - & 10 & $92.3 \%$ & $6.1 \%$ & $1.6 \%$ & 356 & $+18.6 \%$ \\
\hline & 400 & - & 10 & $93.3 \%$ & $6.5 \%$ & $0.2 \%$ & 475 & $+18.7 \%$ \\
\hline \multirow[t]{4}{*}{ Two-Stage } & 200 & 15 & 5 & $97.3 \%$ & $2.3 \%$ & $0.4 \%$ & 223 & $+11.5 \%$ \\
\hline & 300 & 15 & 5 & $96.5 \%$ & $3.4 \%$ & $0.1 \%$ & 280 & $-6.5 \%$ \\
\hline & 400 & 15 & 5 & $96.7 \%$ & $3.2 \%$ & $0.1 \%$ & 448 & $+12.0 \%$ \\
\hline & 500 & 15 & 5 & $95.1 \%$ & $4.2 \%$ & $0.7 \%$ & 558 & $+11.6 \%$ \\
\hline \multirow[t]{3}{*}{ Two-Stage } & 200 & 15 & 10 & $95.5 \%$ & $4.0 \%$ & $0.5 \%$ & 230 & $+15.0 \%$ \\
\hline & 300 & 15 & 10 & $92.5 \%$ & $6.2 \%$ & $1.3 \%$ & 350 & $+16.7 \%$ \\
\hline & 400 & 15 & 10 & $89.5 \%$ & $8.5 \%$ & $2.0 \%$ & 475 & $+18.7 \%$ \\
\hline \multirow[t]{3}{*}{ Two-Stage } & 200 & 25 & 10 & $95.5 \%$ & $3.3 \%$ & $1.2 \%$ & 224 & $+12.0 \%$ \\
\hline & 300 & 25 & 10 & $92.5 \%$ & $6.2 \%$ & $1.3 \%$ & 345 & $+15.0 \%$ \\
\hline & 400 & 25 & 10 & $91.9 \%$ & $6.3 \%$ & $1.8 \%$ & 477 & $+19.2 \%$ \\
\hline
\end{tabular}

Table 4: Tabulated results of the gridded Faraday probe investigation of the NASA-173GT.

\begin{tabular}{|c|c|c|c|c|c|c|c|c|c|c|}
\hline $\begin{array}{l}\text { Thruster } \\
\text { Config. }\end{array}$ & $\begin{array}{l}\mathrm{V}_{\text {accel }} \\
{[\mathrm{V}]}\end{array}$ & $\begin{array}{l}\mathrm{I}_{\text {accel }} \\
{[\mathrm{A}]}\end{array}$ & $\begin{array}{l}\mathrm{I}_{\text {ion }} \\
{[\mathrm{A}]}\end{array}$ & $\begin{array}{c}\dot{m}_{\text {anode }} \\
{[\mathrm{mg} / \mathrm{s}]}\end{array}$ & $\begin{array}{c}\beta_{0.45 \mathrm{~m}} \\
{\left[^{\circ}\right]}\end{array}$ & $\begin{array}{c}\beta_{0.95 \mathrm{~m}} \\
\left.{ }^{\circ}\right]\end{array}$ & $\begin{array}{c}\mathrm{I}_{\mathrm{GP}-0.45 \mathrm{~m}} \\
{[\mathrm{~A}]}\end{array}$ & $\begin{array}{c}\mathrm{I}_{\mathrm{GP}-0.95 \mathrm{~m}} \\
{[\mathrm{~A}]}\end{array}$ & $\begin{array}{c}\mathrm{I}_{\mathrm{C}-0.45 \mathrm{~m}} \\
{[\mathrm{~A}]}\end{array}$ & $\begin{array}{c}\mathrm{I}_{\mathrm{C}-0.95 \mathrm{~m}} \\
{[\mathrm{~A}]}\end{array}$ \\
\hline Single-Stage & 400 & 11.8 & - & 10 & 41 & 48 & 5.39 & 7.66 & 5.59 & 8.27 \\
\hline \multirow[t]{4}{*}{ Two-Stage } & 200 & 5.4 & 15 & 5 & 48 & 57 & 2.31 & 3.32 & 2.37 & 3.43 \\
\hline & 300 & 5.8 & 15 & 5 & 44 & 53 & 2.42 & 3.51 & 2.47 & 3.67 \\
\hline & 400 & 6.0 & 15 & 5 & 45 & 53 & 2.36 & 3.34 & 2.41 & 3.50 \\
\hline & 500 & 6.3 & 15 & 5 & 44 & 51 & 2.41 & 3.27 & 2.46 & 3.43 \\
\hline \multirow[t]{5}{*}{ Two-Stage } & 100 & 4.7 & 25 & 5 & 59 & 67 & 1.54 & 2.10 & 1.58 & 2.20 \\
\hline & 200 & 5.4 & 25 & 5 & 48 & 56 & 2.18 & 3.07 & 2.23 & 3.21 \\
\hline & 300 & 5.7 & 25 & 5 & 45 & 52 & 2.28 & 3.19 & 2.33 & 3.33 \\
\hline & 400 & 6.0 & 25 & 5 & 47 & 53 & 2.34 & 3.23 & 2.39 & 3.38 \\
\hline & 500 & 6.3 & 25 & 5 & 44 & 52 & 2.40 & 3.27 & 2.45 & 3.43 \\
\hline \multirow[t]{4}{*}{ Two-Stage } & 100 & 11.7 & 15 & 10 & 61 & 72 & 3.93 & 5.03 & 4.08 & 5.43 \\
\hline & 200 & 11.4 & 15 & 10 & 45 & 52 & 5.49 & 7.49 & 5.69 & 8.08 \\
\hline & 300 & 11.7 & 15 & 10 & 42 & 48 & 5.48 & 7.64 & 5.68 & 8.25 \\
\hline & 400 & 11.9 & 15 & 10 & 39 & 45 & 5.54 & 7.79 & 5.74 & 8.41 \\
\hline \multirow[t]{4}{*}{ Two-Stage } & 100 & 11.2 & 25 & 10 & 60 & 71 & 3.85 & 4.91 & 3.99 & 5.30 \\
\hline & 200 & 11.1 & 25 & 10 & 45 & 56 & 5.40 & 7.35 & 5.60 & 7.93 \\
\hline & 300 & 11.5 & 25 & 10 & 43 & 49 & 5.50 & 7.87 & 5.70 & 8.49 \\
\hline & 400 & 11.8 & 25 & 10 & 41 & 46 & 5.50 & 7.65 & 5.70 & 8.25 \\
\hline
\end{tabular}

\section{Acknowledgments}

The authors would like to acknowledge the support of this research by NASA through contract NGT3-52348 and NAG3-2307 (David Jacobson, technical monitor for both grants). The author would like to thank David Jacobson, 
David Manzella, John Foster, and Robert Jankovsky for all the suggestions and comments. The authors would also like to thank the technical support staff of the Electric Propulsion and Power Branch at NASA GRC with special acknowledgment to Mr. Kevin L. Blake.

\section{References}

[1] G. W. Butler, J. L. Yuen, S. O. Tverdokhlebov, A. V. Semenkin, A. V. Kochergin, A. E. Solodukhin, and R. S. Jankovsky, "Multimode, High Specific Impulse Hall Thruster Technology," presented at Joint Propulsion Conference, AIAA-00-3254, Huntsville, AL, 2000.

[2] R. S. Jankovsky, D. T. Jacobson, C. J. Sarmiento, L. R. Piñero, D. H. Manzella, R. R. Hofer, and P. Y. Peterson, "NASA's Hall Thruster Program 2002," presented at Joint Propulsion Conference, AIAA-02-3675, Indianapolis, Indiana, 2002.

[3] R. R. Hofer, "Development and Characterization of High-Efficiency, High-Specific Impulse Xenon Hall Thrusters," in Department of Aerospace Engineering. Ann Arbor, MI: The University of Michigan, 2004.

[4] R. Hofer, P. Peterson, and A. Gallimore, "A High Specific Impulse Two-Stage Hall Thruster with Plasma Lens Focusing," presented at International Electric Propulsion Conference, IEPC-01-036, Pasadena, Ca, 2001.

[5] B. Pote and R. Tedrake, "Performance of a High Specific Impulse Hall Thruster," presented at International Electric Propulsion Conference, IEPC-01-35, Pasadena, Ca, 2001.

[6] D. T. Jacobson, R. S. Jankovsky, V. K. Rawlin, and D. H. Manzella, "High Voltage TAL Performance," presented at Joint Propulsion Conference, AIAA-01-3777, Salt Lake City, UT, 2001.

[7] D. H. Manzella, D. T. Jacobson, and R. S. Jankovsky, "High Voltage SPT Performance," presented at Joint Propulsion Conference, AIAA-01-3774, Salt Lake City, UT, 2001.

[8] R. Hofer and A. D. Gallimore, "The Role of Magnetic Field Topography in Improving the Performance of HighVoltage Hall Thrusters," presented at Joint Propulsion Conference, AIAA-02-4111, Indianapolis, Indiana, 2002.

[9] H. R. Kaufman, "Technology of Closed-Drift Thrusters," AIAA Journal, Vol. 23, No. 1, pp. 78-87, 1985.

[10] F. S. Gulczinski, "Examination of the Structure and Evolution of Ion Energy Properties of a 5 Kw Class Laboratory Hall Effect Thruster at Various Operational Conditions," in Department of Aerospace Engineering. Ann Arbor, MI: The University of Michigan, 1999.

[11] J. M. Haas, "Low-Perturbation Interrogation of the Internal and Near-Field Plasma Structure of a Hall Thruster Using a High-Speed Probe Positioning System," in Department of Aerospace Engineering. Ann Arbor, MI: The University of Michigan, 2001.

[12] J. M. Haas, F. S. G. III, and A. D. Gallimore, "Performance characteristics of a 5 kW laboratory Hall thruster," presented at Joint Propulsion Conference, AIAA-98-3503, Cleveland, Oh, 1998.

[13] P. Peterson, J. M. Haas, and A. D. Gallimore, "Experimental Investigation of a Hall Thruster Internal Magnetic Field Topography," presented at International Electric Propulsion Conference, IEPC-01-030, Pasadena, Ca, 2001.

[14] F. S. Gulczinski and A. D. Gallimore, "Field Ion Energy and Species Measurements of a 5-kW Hall Thruster," Journal of Propulsion and Power, Vol. 17, No. 2, pp. 418-427, 2001.

[15] T. B. Smith, "Deconvolution of Ion Velocity Distributions from Laser-Induced Fluorescence Spectra of Xenon Electrostatic Thruster Plumes," in Department of Aerospace Engineering. Ann Arbor, MI: The University of Michigan, 2003.

[16] G. J. Williams, T. B. Smith, F. S. Gulczinski, and A. D. Gallimore, "Correlating Laser Induced Fluorescence and Molecular Beam Mass Spectrometry Ion Energy Distributions," Journal of Propulsion and Power, Vol. 18, No. 2, pp. 489-491, 2002.

[17] G. J. Williams, T. B. Smith, F. S. Gulczinski, B. E. Beal, A. D. Gallimore, and R. P. Drake, "Laser Induced Fluorescence Measurement of Ion Velocities in the Plume of a Hall Effect Thruster," presented at Joint Propulsion Conference, AIAA-99-2424, Los Angeles, Ca, 1999.

[18] M. Walker and A. D. Gallimore, "Hot Flow Pressure Map of a Vacuum Facility as a Function of Flow Rate to Study Facility Effects," presented at Internal Electric Propulsion Conference, IEPC-03-077, Toulouse, France, 2003.

[19] M. Walker, R. Hofer, and A. D. Gallimore, "The Effects of Nude Faraday Probe Design and Vacuum Facility Backpressure on the Measured Ion Current Density Profile of Hall Thruster Plumes," presented at Joint Propulsion Conference, AIAA-02-4253, Indianapolis, Indiana, 2002.

[20] P. Wilbur, "Broad Beam Ion Sources," Course Notes for ME-567 at Colorado State University.

[21] J. A. Menart and M. J. Patterson, "Magnetic circuit for enhanced discharge chamber performance of a small ion thruster," presented at Joint Propulsion Conference, AIAA-98-3343, Cleveland, Oh, 1998.

[22] J. S. Sovey, "Improved Ion Containment Using a Ring-Cusp Ion Thruster," Journal of Spacecraft, Vol. 21, No. 5, pp. 488-495, 1983.

[23] J. E. Foster and M. J. Patterson, "Internal Plasma Properties and Enhanced Performance of 8-Centimeter Ion Thruster Discharge," Journal of Propulsion and Power, Vol. 17, No. 2, pp. 428-432, 2001.

[24] M. J. Patterson, S. P. Grisnik, and G. C. Soulas, "Scaling of Ion Thrusters to Low Power," presented at Internal Electric Propulsion Conference, IEPC-97-098, Cleveland, OH, 1997. 
[25] H. R. Kaufman, "Technology of Electron Bombardment Ion Thrusters," Advances in Electron and Electron Physics, Vol. 36, pp. 266-272, 1974.

[26] M. J. Patterson, "Low-power ion thruster development status," presented at Joint Propulsion Conference, AIAA-983347, Cleveland, Oh, 1998.

[27] J. R. Brophy, "NASA's Deep Space 1 Ion Engine," Review of Scientific Instruments, Vol. 73, No. 2, pp. 1071-1078, 2002.

[28] L. S. Mason, R. Jankovsky, and D. Manzella, "1000 Hours of Testing on a 10 Kilowatt Hall Effect Thruster," presented at Joint Propulsion Conference, AIAA-01-3773, Salt Lake City, UT, 2001.

[29] D. Jacobson, "High Voltage TAL Erosion Characterization," presented at Joint Propulsion Conference, AIAA-02-4257, Indianapolis, Indiana, 2002.

[30] T. W. Haag, "Thrust stand for high-power electric propulsion devices," Review of Scientific Instruments, Vol. 62, No. $5,1991$.

[31] T. W. Haag and M. Osborn, "RHETT/EPDM performance characterization," presented at Internal Electric Propulsion Conference, IEPC-97-107, Cleveland, OH, 1997.

[32] S.-W. Kim and A. D. Gallimore, "Plume Study of a 1.35-kW SPT-100 Using an ExB Probe," Journal of Spacecraft and Rockets, Vol. 39, No. 6, pp. 904-909, 2002.

[33] S.-W. Kim, "Experimental Investigations of Plasma Parameters and Species-Dependent Ion Energy Distribution in the Plasma Exhaust Plume of a Hall Thruster," in Department of Aerospace Engineering. Ann Arbor, MI: The University of Michigan, 1999.

[34] R. L. Seliger, "ExB mass-separator design," Journal of Applied Physics, Vol. 43, No. 5, 1972.

[35] R. Hofer and A. D. Gallimore, "Ion Species Fractions in the Far-Field Plume of a High-Specific Impulse Hall Thruster," presented at Joint Propulsion Conference, AIAA-03-5001, Huntsville, Alabama, 2003.

[36] J. H. Moore, C. C. Davis, and M. A. Coplan, Building Scientific Apparatus, second ed. College Park: Perseus Books, 1989.

[37] I. H. Hutchinson, Principles of Plasma Diagnostics. Massachusetts: Cambridge University Press, 2000.

[38] J. M. Fife, W. A. Hargus, D. A. Jaworske, C. Sarmiento, L. S. Mason, J. R., J. S. Snyder, S. Malone, J. M. Haas, and A. D. Gallimore, "Spacecraft interaction test results of the high performance Hall system SPT-140," presented at Joint Propulsion Conference, AIAA-00-3521, Huntsville, AL, 2000.

[39] D. Manzella, "Hall Thruster Ion Beam Characterization," presented at Joint Propulsion Conference, AIAA-95-2927, San Diego, CA, 1995.

[40] J. S. Sovey and M. J. Patterson, "Ion Sputtering in Electric Propulsion Facilities," presented at Joint Propulsion Conference, AIAA-91-2117, Sacramento, CA, 1991.

[41] V. Kim, "Main Physical Features and Processes Determining the Performance of Stationary Plasma Thrusters," Journal of Propulsion and Power, Vol. 14, No. 5, pp. 736-743, 1998.

[42] R. Hofer and R. Jankovsky, "A Hall Thruster Performance Model Incorporating the Effects of a Multiply-Charged Plasma," presented at Joint Propulsion Conference, AIAA-01-3322, Salt Lake City, UT, 2001. 